\title{
Evolution of NADPH Oxidase Inhibitors: Selectivity and Mechanisms for Target Engagement
}

\author{
Sebastian Altenhöfer, Kim A. Radermacher, Pamela W.M. Kleikers, Kirstin Wingler, and Harald H.H.W. Schmidt
}

\begin{abstract}
Significance: Oxidative stress, an excess of reactive oxygen species (ROS) production versus consumption, may be involved in the pathogenesis of different diseases. The only known enzymes solely dedicated to ROS generation are nicotinamide adenine dinucleotide phosphate (NADPH) oxidases with their catalytic subunits (NOX). After the clinical failure of most antioxidant trials, NOX inhibitors are the most promising therapeutic option for diseases associated with oxidative stress. Recent Advances: Historical NADPH oxidase inhibitors, apocynin and diphenylene iodonium, are un-specific and not isoform selective. Novel NOX inhibitors stemming from rational drug discovery approaches, for example, GKT137831, ML171, and VAS2870, show improved specificity for NADPH oxidases and moderate NOX isoform selectivity. Along with NOX2 docking sequence (NOX2ds)-tat, a peptide-based inhibitor, the use of these novel small molecules in animal models has provided preliminary in vivo evidence for a pathophysiological role of specific NOX isoforms. Critical Issues: Here, we discuss whether novel NOX inhibitors enable reliable validation of NOX isoforms' pathological roles and whether this knowledge supports translation into pharmacological applications. Modern NOX inhibitors have increased the evidence for pathophysiological roles of NADPH oxidases. However, in comparison to knockout mouse models, NOX inhibitors have limited isoform selectivity. Thus, their use does not enable clear statements on the involvement of individual NOX isoforms in a given disease. Future Directions: The development of isoform-selective NOX inhibitors and biologicals will enable reliable validation of specific NOX isoforms in disease models other than the mouse. Finally, GKT137831, the first NOX inhibitor in clinical development, is poised to provide proof of principle for the clinical potential of NOX inhibition. Antioxid. Redox Signal. 23, 406-427.
\end{abstract}

\section{Introduction}

$\mathbf{O}$ XIDATIVE STRESS IS a likely common underlying mechanism for multiple diseases such as cardiovascular diseases, neurodegenerative disorders, and cancer. The term oxidative stress describes the disturbance of the redox hemostasis in favor of increased levels of reactive oxygen species (ROS). It can be caused either by decreased antioxidant capacity due to low concentrations of antioxidants and impaired antioxidant enzyme activity, and/or by increased ROS production due to enhanced activity of ROS-producing entities. However, at appropriate concentrations and in a clearly defined space, ROS also have essential functions in cellular signaling processes. For example, ROS regulate cell proliferation, differentiation and migration, innate immune response, extracellular matrix dynamics, vascular tone, as well as inflammation $(13,180,182)$. Therefore, the disturbance of the redox hemostasis in the other direction, that is, decreased levels of ROS, called reductive stress, is gaining more and more attention. The state is caused by elevated levels of reducing equivalents, such as an increased ratio of nicotinamide adenine dinucleotide phosphate (NADPH)/ $\mathrm{NADP}^{+}$or of reduced glutathione (GSH)/oxidized glutathione $(141,193)$. This imbalance in redox hemostasis might partly explain the antioxidant paradox in cardiovascular diseases: Although it is well established that oxidative stress

Department of Pharmacology, Cardiovascular Research Institute Maastricht (CARIM), Maastricht University, Maastricht, the Netherlands. 
plays a major role in the development of cardiovascular diseases, hardly any clinical study testing antioxidant supplementation to prevent or treat cardiovascular diseases resulted in improved outcomes (16). In contrast, mortality was even increased in some trials using, for example, vitamin $\mathrm{E}$ supplementation (108). Next to potentially causing reductive stress and thus worsening cardiovascular outcome rather than improving it, the lack of specificity of antioxidants toward a certain ROS at a specific site might have contributed to their clinical failure [for a more detailed discussion, the reader is referred to $(47,66,182)]$. Since antioxidant supplementation proved to be non-effective or even detrimental, another therapeutic strategy to fight oxidative stress evolved: Targeting the sources of pathophysiological ROS rather than trying to scavenge ROS in a generalized fashion after they have been produced.

Several enzymes in the body are capable of producing ROS. Among them are xanthine oxidase (104), cytochrome P450 oxidases (50), lipoxygenases (192), uncoupled nitric oxide synthase (NOS) (174), NADPH oxidases (catalytic subunit of NADPH oxidases [NOX]) (13), monoamino oxidases (48), and the mitochondrial electron transport chain (163). The majority of these enzymes only produce ROS after they have been damaged by ROS, as, for example, is the case for uncoupled endothelial nitric oxide synthase (eNOS) (174) and xanthine oxidase (104). In contrast, NADPH oxidases produce ROS as their primary and sole function. They are widely distributed throughout different tissues and organs and were suggested to play important roles in multiple diseases associated with oxidative stress [reviewed in (13)]. Therefore, NADPH oxidases are considered prime target candidates for the treatment of these diseases. In that setting, various compounds have been postulated as NADPH oxidase inhibitors.

Here, we give an overview of the most important NADPH oxidase inhibitor candidates and critically review their use in in vivo proof-of-concept studies of NADPH oxidase inhibition in various diseases.

\section{The NADPH Oxidase Enzyme Family}

The NADPH oxidase enzyme family contains a homologous catalytic subunit, NOX. Seven NOX members exist that are characterized by at least six trans-membrane helices containing two iron-heme prosthetic groups, as well as a flavin adenine dinucleotide (FAD) and an NAPDH-binding domain in the cytosolic c-terminus (Fig. 1). The NOX isoforms dual oxidase 1 (DUOX1) and 2 (DUOX2) have an additional trans-membrane domain and an extracellular Nterminus that contains a peroxidase-like domain. Therefore, they were termed DUOX1 and DUOX2. However, according to current knowledge, human DUOX enzymes do not display any peroxidase activity (105-107). Therefore, others and we suggest that the field considers terming these isoforms NOX6 and NOX7 rather than DUOX1 and DUOX2.

NOX enzymes differ in enzymatic complex composition, modes of activation, and the products of their enzymatic reaction. Most NOX isoforms require at least one cytosolic or membrane-bound binding partner for activity (Fig. 1). NOX1-4 associate with the stabilizing membrane protein, p22 $2^{\text {phox }}$. DUOX1 and DUOX2 associate with their respective maturation factors, the membrane proteins DUOXA1 and
DUOXA2. All other associated proteins can be classified as activators or organizers (126). The activating proteins activate or increase the enzymatic ROS production. These are p $67^{\text {phox }}$ and $\mathrm{p} 40^{\text {phox }}$ for NOX2 and its analogue NOXA1 for NOX1. The organizer proteins set the structural requirements for the activation or binding of the activator proteins. $\mathrm{p} 47^{\text {phox }}$ stabilizes the complex formation for NOX2. NOXO1 enables the active complex formation for NOX1 and NOX3. In addition, NOX1-3 seems to require the small GTPase, Rac, for activity, although the role of Rac for NOX3 in vivo is still under debate $(171,172)$.

Recently, additional NOX-interacting partners have been suggested to bind to and enhance the activity of NOX4, such as polymerase (DNA-directed) delta-interacting protein 2 in focal adhesions (102), and activated Toll-like receptor-4 $(130,168)$. Additional factors, which might bind and activate both NOX1 and NOX4, such as protein disulphide isomerase (75) and tyrosine kinase substrate with 4/5 SH3 domain (43, 57), have been identified. Furthermore, heat shock protein 90 (Hsp90) has been suggested to bind to and regulate the stabilities of NOX1, NOX2, and NOX5; while Hsp70 most likely facilitates the degradation of NOX2 and NOX5 (28, 29). However, heterologous expression in cells may influence the expression of other proteins and interfere with protein processing and folding. In addition, in vitro systems may lack interacting partners that are important in vivo. Thus, there may be even yet undiscovered NOX binding partners. Accordingly, the physiological roles and tissue specificities of these recently reported protein-protein interactions and stabilization-destabilization mechanisms by chaperones for NOX activity regulation need to be further analyzed in vivo.

NOX isoforms differ not only in their subunit requirements, but also in their modes of activation. NOX1-3 seem to be dynamically activated or deactivated by complex formation with the NOX regulatory proteins (NOXA1 and NOXO1 for NOX1; $67^{\text {phox }}, \mathrm{p} 47^{\text {phox }}$, and $440^{\text {phox }}$ for NOX2; and NOXO1 for NOX3). NOX5 and DUOX 1/2 are activated intra-molecularly by the binding of calcium to their intracellular EF-hand motifs $(8,111,146)$. The calcium sensitivity of NOX5 can be further enhanced by the binding of calmodulin or Hsp90 to the C-terminus of the EF-hand motifs $(28,170)$ and by phosphorylation (159). DUOX1 and DUOX2 bind their respective maturation factors, DUOXA1 and DUOXA2, enabling translocation from the endoplasmic reticulum to the plasma membrane before they can be activated (63).

NOX4 is an exceptional member of the NOX family. Although binding proteins have been suggested to enhance NOX4 activity (see earlier), these do not seem to be required for NOX4's basal activity, at least in vitro. According to the current knowledge, NOX4 is constitutively active and is mainly regulated via regulation of its expression.

All NOX isoforms catalyze the transfer of two electrons from NAPDH via their FAD domain and two iron-heme prosthetic groups to molecular oxygen. While NOX1, NOX2, NOX3, and NOX5 generate superoxide, NOX4, DUOX1, and DUOX2 mainly release hydrogen peroxide. In case of NOX4, the produced superoxide seems to be trapped and dismutated to hydrogen peroxide in an extracellular loop of NOX4 (169). For DUOX1 and DUOX2, the maturation factors DUOXA1 and DUOXA2 seem to be responsible for the type of ROS produced and released $(72,112)$. However, since iron-heme 
Hetero

Oligomer-

dependent
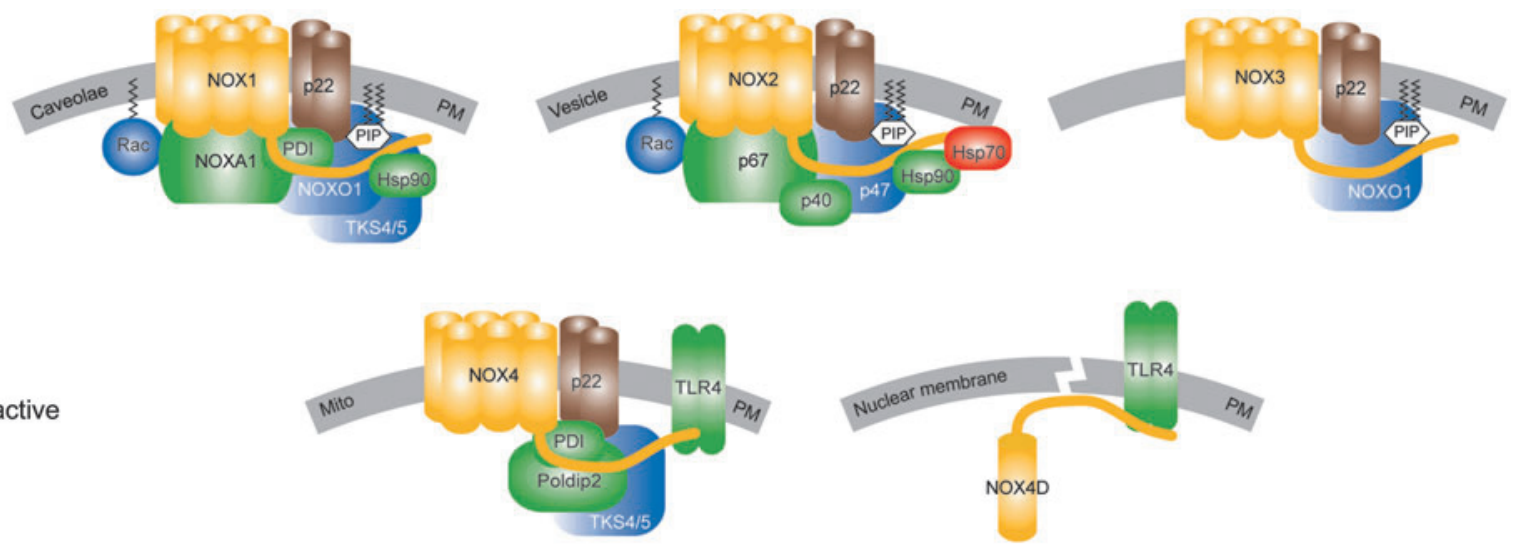

Constitutively active
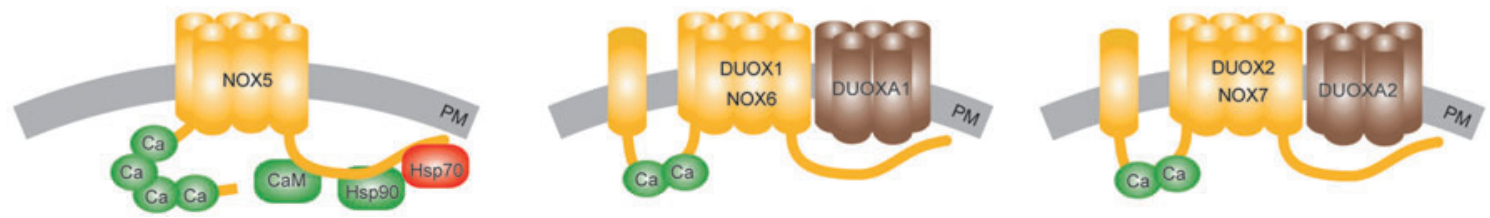

FIG. 1. The NADPH oxidase enzyme family. All NOX isoforms (yellow) are membrane proteins that are localized in the PM or cellular compartments' membranes (gray). Stabilizing or maturation factors of NOX are presented in brown, activating binding partners are in green, complex organizing binding partners are in blue, and destabilizing binding partners are in red. In addition to the PM localization, NOX1 was also found in caveolae (71). NOX2 is heavily expressed in the plasma membrane of phagocytic vesicles. NOX4 was found in several sub-cellular compartments' membranes, for example, mitochondria (1, 18, 91). A soluble NOX4 splice variant, $\operatorname{NOX} 4 \mathrm{D}(14,62,130)$, lacking five out of six transmembrane domains, was suggested in the nucleus and nucleolus (4). Although localization of NOX4 (135) and NOX5 (9, 170) in the ER was suggested, a physiological localization or associated function was not shown until now. Activation of NOX1-3 depends on the formation of hetero oligomeric complexes. NOX1 is activated by the binding of its organizer NOXO1, which along with the small GTPase, Rac, enables the binding of the NOXA1 to fully activate the complex. NOX2 is activated in a similar manner by its organizer proteins, $\mathrm{p} 47^{\text {phox }}$ and Rac, that enable binding of the activator protein, p67 ${ }^{\text {phox }}$. The activation of NOX2 can be further enhanced by the binding of $\mathrm{p} 40^{\text {phox }}$ to the complex. Although NOX3 requires NOXO1 for activation (87), its requirement of activator proteins is still under debate but likely. NOXA1 seems to be capable of activating NOX3, but its role still needs to be confirmed in vivo $(31,32,121,171,172)$. NOX 4 is the only NOX isoform that seems to be constitutively active in the absence of any cytosolic binding factor. However, its activity can be enhanced by binding proteins such as protein Poldip2 (102) and activated TLR4 $(14,130,168)$. TLR-4 also seems to bind to the NOX4D splice variant (14). Recently, an analogue of NOXO1, the Tks4/5, and PDI have been found to bind and activate NOX1 and NOX4 (43, 57). Hsp90 was shown to enhance the activities of NOX1, NOX2, and NOX5; while Hsp70 binds to NOX2 and NOX5, leading to degradation of the protein by ubiquitination $(28,29)$. However, the roles of the latter two binding proteins need further confirmation. NOX5, NOX6/ DUOX1, and NOX7/DUOX2 are mainly activated by calcium via their calcium binding sites. The calcium sensitivity of NOX5 can be enhanced by calmodulin (170) and Hsp90 (28). Up to date, no calcium sensitizing or other binding partners of DUOX1/NOX6 or DUOX2/NOX7 have been identified. DUOX, dual oxidase; ER, endoplasmic reticulum; Hsp, heat shock protein; NADPH, nicotinamide adenine dinucleotide phosphate; NOX, catalytic subunit of NADPH oxidases; NOXA1, NOX activator-1; NOXO1, NOX organizer-1; PDI, protein disulfide isomerase; PM, plasma membrane; Poldip2, polymerase (DNAdirected) delta-interacting protein 2; TKS4/5, tyrosine kinase substrate with 4/5 SH3 domains; TLR4, toll-like receptor-4. To see this illustration in color, the reader is referred to the web version of this article at www.liebertpub.com/ars

groups generally perform single-electron transfers, it is likely that DUOX1 and DUOX2 release hydrogen peroxide in a similar mechanism as proposed for NOX4.

NADPH oxidases are widely distributed through different tissues and cell types. For a full list, we refer the reader to the review of Bedard and Krause (13). Briefly, NOX1 is mainly expressed in the colon, NOX2 in phagocytes and B lymphocytes, NOX3 in the inner ear and some fetal tissues, NOX4 in the kidney and the blood vessels, and NOX5 in lymphoid tissue and testis. Notably, NOX5 is not expressed in rats and mice. Therefore, the information on NOX5 localization and function is limited. DUOX1 and DUOX-2 are most abundantly expressed in thyroid and lung tissue.

Often, suggested roles for NAPDH oxidases evolved mainly from tissue expression studies. For instance, the potential roles of NOX1, NOX2, NOX4, and NOX5 were based on their expression in cardiovascular tissues (93), of NOX2 and NOX4 in brain tissue $(23,140)$, of NOX2, NOX 4 , and DUOX2 in the lung $(26,67,173)$, as well as of NOX1, NOX2, NOX4, and NOX5 in cancer cells and tumors (17). However, whether or which role NOX isoforms might play in health and disease in these tissues is still the subject of ongoing research.

\section{NADPH Oxidase Inhibitors}

\section{Historical small-molecule NADPH oxidase inhibitors}

Several small molecules have been and are still being used as direct NADPH oxidase inhibitors. Although many of these suggested inhibitors inhibit NADPH oxidase activity, the majority of these historical inhibitors are unspecific, due to several off-target effects or the inhibition of features of NADPH oxidases that are not unique for NOX enzymes but 
also occur in other (ROS generating) enzymes. These unspecific inhibitors include the most frequently used NOX inhibitors, diphenylene iodonium (DPI) and apocynin, which have been proved to be unspecific as reviewed earlier in detail $(2,77,157,182)$. Briefly, DPI acts as a general flavoprotein inhibitor and, therefore, also inhibits eNOS, xanthine oxidase, and proteins of the mitochondrial electron transport chain $(2,124,125)$. Apocynin shows intrinsic antioxidant activity, that is, ROS-scavenging properties (70), and it inhibits rho kinases (151). Other proposed NOX inhibitors such as 4-(2-aminoethyl)-benzenesulphonyl fluoride (AEBSF) or plumbagin (44) are used less frequently. However, they do not only have low potencies for NADPH oxidase but also unspecific effects. For example, AEBSF inhibits serine proteases (42), and plumbagin acts as an antioxidant and exerts several other unspecific effects such as NF-kappa-B inhibition and bactericidal actions [reviewed in ref. (127)]. In addition, none of the inhibitors mentioned here exhibits significant selectivity for any of the NOX isoforms. Furthermore, some inhibitors interfere with ROS detection dyes (181). Therefore, their use likely results in overestimations of the actual NADPH oxidase-linked effects. In conclusion, historical NADPH oxidase inhibitors have several weaknesses, and their use does not emable drawing any conclusions on the involvement of NOX in a given system. Obviously, more specific compounds are needed.

\section{Novel small-molecule NADPH oxidase inhibitors}

Characteristics of the ideal NADPH oxidase inhibitor. The ideal NADPH oxidase inhibitor should neither scavenge ROS, that is, not have antioxidant actions, nor in- hibit other flavoproteins or NADPH-dependent proteins. NADPH oxidase inhibitors should further not influence the expression levels of NOX or their respective binding partners. They also should not interfere with upstream signaling pathways of NOX activation but rather inhibit NADPH oxidase activity directly. In addition to NADPH oxidase specificity, isoform selectivity for one of the NOX isoforms is desirable.

Recently, several new small-molecule NADPH oxidase inhibitors have been identified by drug screening approaches and characterized with regard to NOX isoform selectivity and potential unspecific effects $(52,58,92)$. Growing knowledge on the biochemical properties of NADPH oxidases and their mechanisms of activation also enabled rational inhibitor design (145) followed by the identification of further inhibitors $(76,164)$. In the next few chapters, we will discuss these novel small-molecule NADPH oxidase inhibitors. We summarize their specificity for NOX enzymes (Table 2), NOX isoform selectivity (Table 1), likely mechanisms of action (Fig. 2), reported off-target effects, and their potential feasibility for in vivo proof-of-concept studies.

GKT136901 and GKT137831. GenKyoTex developed the two inhibitors, GKT136901 and GKT137831, exploring structure-activity relationships (SAR) around pyrazolopyridine dione derivatives, which were identified in a highthroughput screen for NOX4 inhibitors (92) (Fig. 3). The GKT compounds potently inhibit NOX1, NOX4, and NOX5 with concentrations with $50 \%$ inhibition of activity $\left(\mathrm{IC}_{50}\right)$ values in the three digit nanomolar range and show $\sim 10-15-$ fold higher $\mathrm{IC}_{50}$ values for NOX2 inhibition (Table 1) $(5,53$, $92,154)$. Inhibition profiles of DUOX1 and DUOX2 are not

Table 1. Isoform Selectivity of Novel Catalytic Subunits of Nicotinamide Adenine Dinucleotide Phosphate Oxidases Inhibitors

\begin{tabular}{|c|c|c|c|c|c|c|c|c|}
\hline \multirow[b]{2}{*}{ Compound } & \multicolumn{8}{|c|}{$I C_{50}(\mu \mathrm{M})$} \\
\hline & NOX1 & NOX2 & NOX3 & NOX4 & NOX5 & DUOX1 & DUOX2 & XO/AO \\
\hline GKT136901 $(92,118)$ & $0.16^{\mathrm{a}, \mathrm{b}}$ & $1530^{\mathrm{a}, \mathrm{b}}$ & & $0.17^{a, b}$ & $0.45^{\mathrm{a}, \mathrm{b}}$ & & & $>30,000^{b}$ \\
\hline GKT137831 (5) & $0.14^{\mathrm{a}, \mathrm{b}}$ & $1750^{\mathrm{a}, \mathrm{b}}$ & & $0.11^{\mathrm{a}, \mathrm{b}}$ & $0.41^{\mathrm{a}, \mathrm{b}}$ & & & $>100^{\mathrm{b}}$ \\
\hline ML171 (58) & $0.25^{\mathrm{c}}$ & $5.00^{\mathrm{c}}$ & $3.00^{\mathrm{c}}$ & $5.00^{\mathrm{c}}$ & & & & 5.50 \\
\hline $\begin{array}{l}\text { VAS2870 }(52,55) \\
\text { VAS } 3947\end{array}$ & & $0.77^{\mathrm{d}}$ & & & & & & \\
\hline $\begin{array}{l}\text { VAS3947 (181) } \\
\text { Celastrol (76) }\end{array}$ & $12.0^{\mathrm{a}}$ & $2.00^{\mathrm{d}}$ & & $13.00^{\mathrm{a}}$ & & & & n.s. ${ }^{\mathrm{e}}$ \\
\hline Celastrol (76) & $0.41^{\mathrm{c}}$ & $0.59^{c}$ & & $2.79^{\mathrm{c}}$ & $3.13^{\mathrm{c}}$ & & & $>100$ \\
\hline Ebselen $(76,164)$ & $0.15^{\mathrm{c}}$ & $0.50^{c}$ & & $>50.0^{\mathrm{c}}$ & $0.70^{\mathrm{a}}$ & & & n.s..$_{f}^{f}$ \\
\hline Perhexiline $(55,85)$ & & $3.0^{\mathrm{d}}$ & & & & & & n.s. ${ }^{f}$ \\
\hline Grindelic acid (89) & & $>20.0^{\mathrm{d}}$ & & $2.06^{\mathrm{c}}$ & $>20.0^{\mathrm{c}}$ & & & n.s. ${ }^{\mathrm{g}}$ \\
\hline NOX2ds-tat (36) & n.s. ${ }^{\text {ah }}$ & $0.74^{\mathrm{a}}$ & & $\mathrm{n} \cdot \mathrm{s}^{\mathrm{a}, \mathrm{h}}$ & & & & n.s. ${ }^{\mathrm{h}}$ \\
\hline NOXA1ds (143) & $0.02^{\mathrm{a}}$ & n.s. ${ }^{\mathrm{a}, \mathrm{h}}$ & & n.s. ${ }^{\mathrm{a}, \mathrm{h}}$ & n.s. ${ }^{\text {a,h }}$ & & & n.s. ${ }^{h}$ \\
\hline Fulvene-5 (15) & & $\sim 5.00^{\mathrm{c}}$ & & $\sim 5.00^{\mathrm{c}}$ & & & & \\
\hline ACD 084 (89) & & $>5.00^{\mathrm{c}}$ & & $3.08^{\mathrm{c}}$ & $>5.00^{\mathrm{c}}$ & & & n.s. ${ }_{b}^{\mathrm{i}}$ \\
\hline Phenantridinones (19) & & & & $0.17^{\mathrm{c}}$ & & & & n.s. ${ }^{\mathrm{h}}$ \\
\hline $\begin{array}{l}\text { Shionogi }(55) \\
\text { S17834 }\end{array}$ & & $0.56^{\mathrm{d}}$ & & & & & & \\
\hline Imipramin blue (117) & & & & $\sim 5.00$ & & & & \\
\hline
\end{tabular}

$\mathrm{IC}_{50}$ values of NOX inhibitors for different NOX isoforms and XO or AO activity are presented as determined in different cellular or cellfree assays as described in the respective publication and indicated with the superscription. The $\mathrm{IC}_{50}$ values that suggest relative NOX isoform selectivity are shown in bold. Only some inhibitors were tested for XO inhibition or ROS-scavenging effects, and inhibition was not significant (n.s.) for some of these compounds.

$\mathrm{IC}_{50}$ values were determined in ${ }^{\mathrm{a}}$ cell-free or lysate assay; ${ }^{\mathrm{b}} K_{\mathrm{i}}$ were published; ${ }^{\mathrm{c}}$ overexpressing cells; ${ }^{\mathrm{d}}$ native cells; ${ }^{\mathrm{e}}$ no significant inhibition for concentrations of approximately $30 \mu M$ or ${ }^{\mathrm{f}} 100 \mu M,{ }^{\mathrm{g}} 20 \mu M,{ }^{\mathrm{h}} 10 \mu M,{ }^{\mathrm{i}} 5 \mu M$.

$\mathrm{AO}$, antioxidant; DUOX, dual oxidase; $\mathrm{IC}_{50}$, concentration with $50 \%$ inhibition of activity; NADPH, nicotinamide adenine dinucleotide phosphate; NOX, catalytic subunit of NADPH oxidases; NOX2ds, NOX2 docking sequence; XO, xanthine oxidase. 


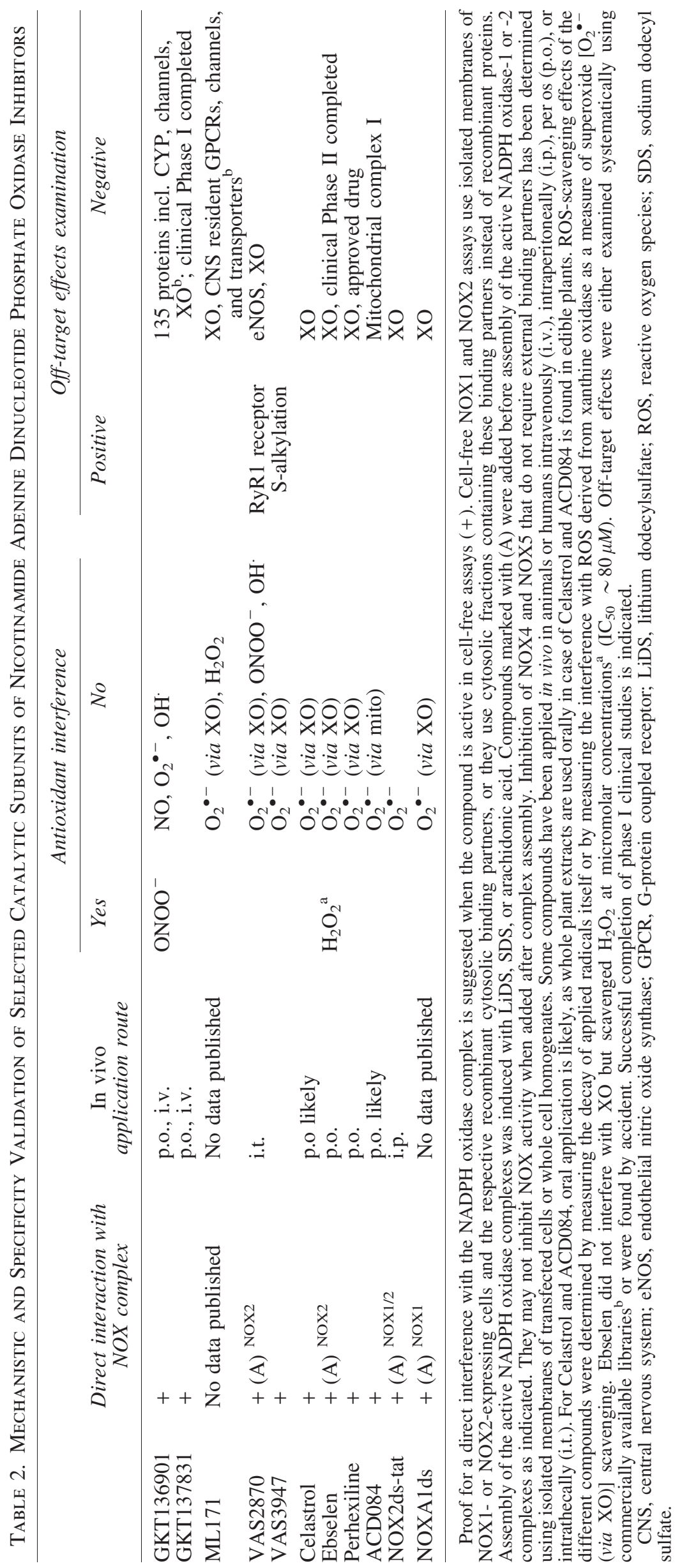




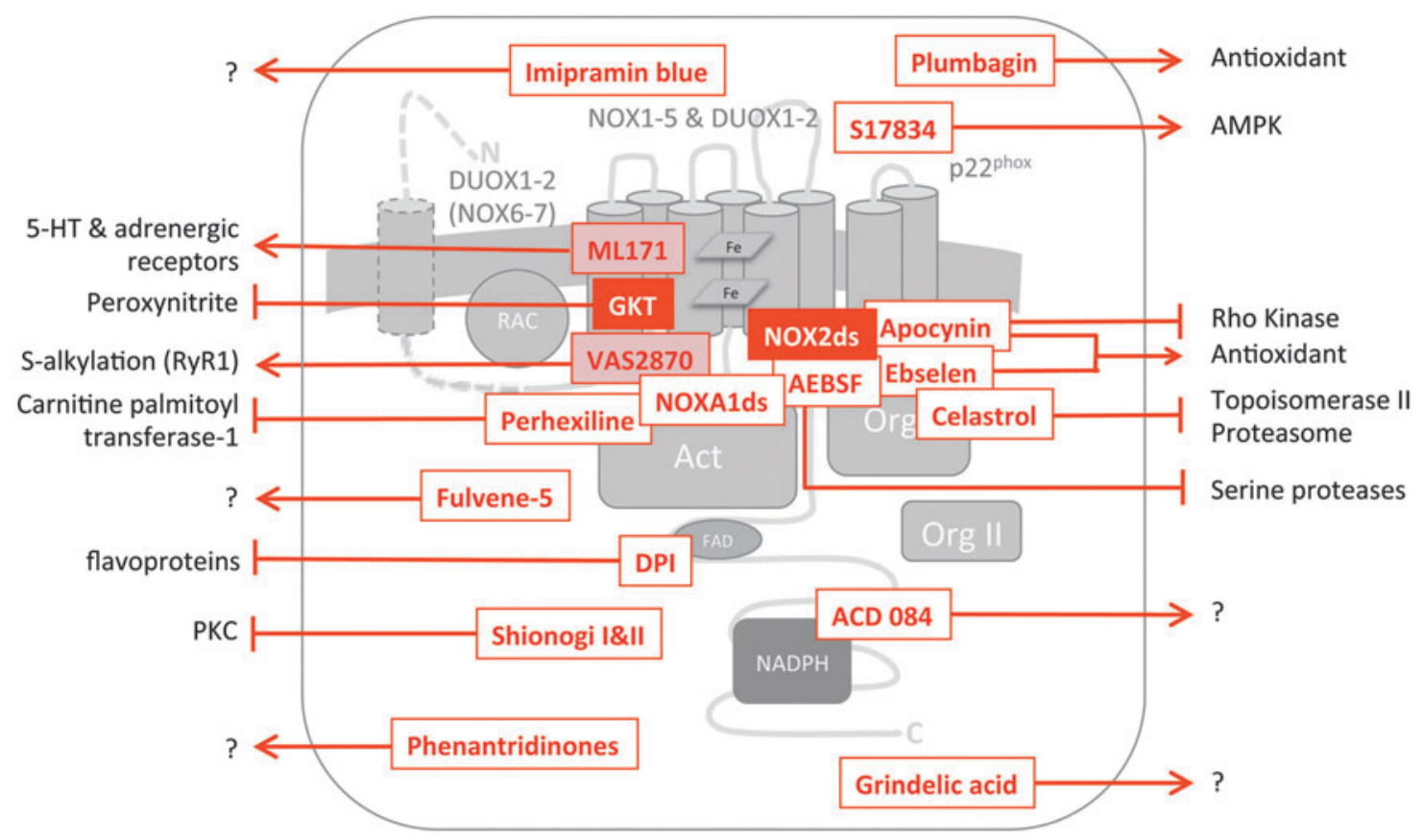

FIG. 2. Mechanisms of NOX inhibition. The scheme shows the general structure of NAPDH oxidase complexes with the catalytic subunits, NOX1-7, in the plasma membrane, the membrane-bound binding partner, p22 ${ }^{\text {phox }}$, one or two organizer binding proteins (Org I and Org II), the small GTPase, Rac, and one activator binding protein (Act). The cytosolic NOX Ctermini have an FAD and an NAPDH binding domain. DUOX1/NOX6 and DUOX2/NOX7 have an additional transmembrane domain and an extracellular N-terminus. Suggested, but not completely validated or unspecific inhibitors of NAPDH oxidase activity are shown in red font, recommended inhibitors in white font on a red background, and partly recommended inhibitors in red font on a pale red background. Inhibitors are recommended if they are specific for NADPH oxidases and show efficacy in cell-free, cellular, and in vivo conditions. Placement of the inhibitors indicates their likely point of interaction, arrows indicate off-target effects, and arrows with question marks indicate insufficient characterization regarding off-target effects. The NOX2ds-tat peptide (145) and AEBSF (42) prevent complex assembly of the respective NOX isoform with its organizer subunit, in case of NOX2ds-tat, NOX2, and p47 ${ }^{\text {phox }}$. AEBSF also inhibits serine proteases. Celastrol (76), ebselen (164), and apocynin $(123,166)$ inhibit the binding of the organizer proteins NOXO1 and p47 ${ }^{\text {phox }}$ to p22 $2^{\text {phox }}$. Ebselen and apocynin are known ROS scavengers. The latter also inhibits rho kinases. Celastrol further inhibits topoisomerase II and the proteasome. NOXA1ds inhibits binding of the respective NOX activator, NOXA1 to NOX1. VAS2870 is very likely an assembly inhibitor with a yet unknown target domain (3). It was shown to alkylate cysteine residues in the RyR1 receptor (167). DPI is a flavoprotein inhibitor. Since ACD 084 inhibited ROS from the NOX4 dehydrogenase domain (89), it may act either on the FAD or NAPDH binding site or as a direct antioxidant. The Shionogi compounds are not NOX inhibitors but prevent the assembly of NADPH oxidase complexes indirectly by the inhibition of protein kinase C (55). Imipramin is a cation and can, therefore, not cross cell membranes. It most likely exerts its NOX inhibition extracellularly. S17834 and plumbagin are polyphenols and most likely scavenge ROS directly. The main target of S17834, however, seems to be AMPK. No mechanisms of action are published for the GKT compounds (GKT136901 and GKT137831) and ML171. GKT136901 scavenges peroxynitrite, and ML171 was reported to inhibit serotonin and adrenergic receptors with very low affinity and potency. AEBSF, 4-(2-aminoethyl)- benzenesulphonyl fluoride; AMP, adenosine monophosphate; AMPK, AMP-activated protein kinase; DPI, diphenylene iodonium; FAD, flavin adenine dinucleotide; NOX2ds, NOX2 docking sequence; ROS, reactive oxygen species. To see this illustration in color, the reader is referred to the web version of this article at www.liebertpub.com/ars

published. Both compounds only inhibit xanthine oxidasederived ROS formation with high $\mathrm{IC}_{50}$ values of $\sim 100 \mu \mathrm{M}$ $(5,154)$ [These $\mathrm{IC}_{50}$ values were estimated from the published concentration response curves $(5,154)]$. However, GKT136901 potently scavenges peroxynitrite, a reactive nitrogen species created from the reaction of superoxide with nitric oxide (150) and dose dependently decreases Amplex Red fluorescence (own, Unpublished observation). While this might be beneficial for the therapeutic efficiency of the compound, it complicates the interpretation of obtained results regarding the participation of NOX enzymes. GKT137831 remains to be tested for this type of radical scavenging properties. With regard to NADPH oxidase in- hibition, only $K_{\mathrm{i}}$ (inhibition constant) values of GKT compounds, generated using the Cheng-Prusoff equation, are published (92). The Cheng-Prusoff equation describes the inhibition constant of a competitive inhibitor with an agonist or substrate (33). To our knowledge, the competitive character of GKT compounds with NADPH has not been analyzed. Thus, the interpretation of these inhibition constants is complex. Nevertheless, GKT136901 and GKT137831 are the best characterized NOX inhibitors currently available, for example, with regard to off-target effects and pharmacokinetics. GKT compounds did not influence tested off-target proteins, including redox-sensitive enzymes, G-proteincoupled receptors (GPCRs), kinases, ion channels, and other 
Pyrazolo pyridines:

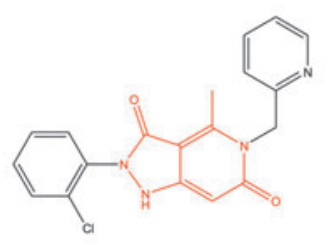

GKT136901

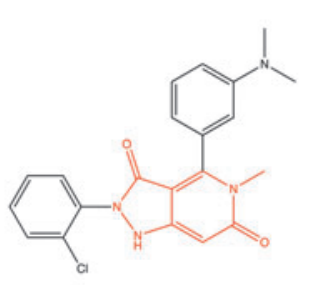

GKT137831

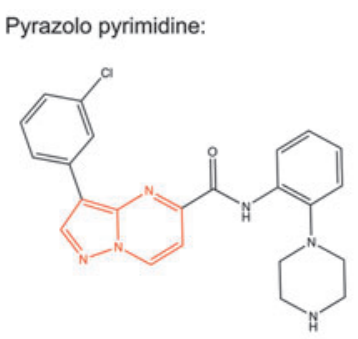

Shionogi
Triazolo pyrimidines:

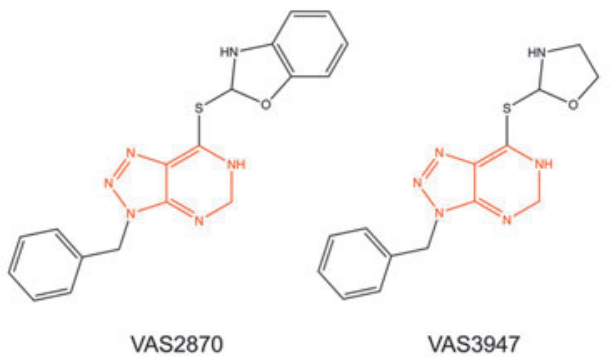

Indoline structures:

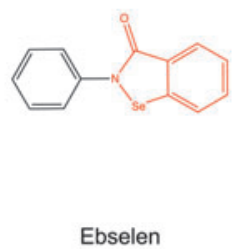

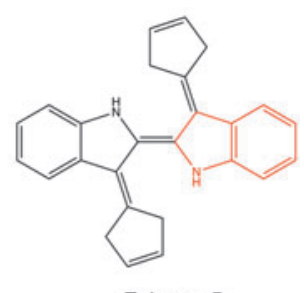

Fulvene-5
FIG. 3. NOX inhibitor structures with scaffold similarities. Some of the novel NOX inhibitors share structural similarities. All inhibitors are planar molecules with heterocyclic indene cores (shown in red) with slightly different sets of nitrogen hetereo atoms. GKT136901 and GKT137831 are based on a pyrazolo pyridine scaffold; the Shionogi compound has a pyrazolo pyrimidine core; VAS2870 and VAS3947 consist of a triazolopyrimidine; while Ebselen and Fulvene-5 share an indoline-like core. To see this illustration in color, the reader is referred to the web version of this article at www.liebertpub.com/ars enzymes. They are orally bio-available and have favorable ADME profiles $(5,92)$. If GKT137831 does not scavenge free radicals, it is the currently best compound for in vivo proof-of-concept studies on the role of NOX enzymes in disease. Furthermore, GKT137831 is already in clinical development (79). Thus, it seems that its properties are more suitable for in vivo use compared with GKT136901.

ML171. The Scripps Research Institute screened 16,000 compounds for NOX1 inhibition and performed limited SAR analysis with commercially available phenothiazines around the most promising hit, 2-(trifluoromethyl)-phenothiazine. They identified 2-acetylphenothiazine (ML171) (Fig. 4) as a potent NOX1 inhibitor (58). ML171 showed $\mathrm{IC}_{50}$ values of 130-250 $\mathrm{n} M$ for NOX1, and of 3-5 $\mu M$ for NOX2-4 (Table 1) as well as for xanthine oxidase (58). It is known that several phenothiazines (e.g., chlorpromazine) act as antagonists on dopamine and serotonin receptors and are clinically used as anti-psychotic drugs. Therefore, ML171 was tested for its ability to inhibit a set of GPCRs, ion channels, and transporter proteins. While several compounds of the promazine class of drugs did not inhibit NOX enzymes, ML171 showed some inhibition of serotonin and adrenergic receptors. Although high $K_{\mathrm{i}}$ values for this off-target inhibition of ML171 were reported, the effects on these receptors need to be excluded before using ML171 for in vivo proof-of-concept studies. However, due to the high degree of similarity to currently used drugs, the pharmacokinetics and safety data of ML171 likely enable the use of this compound in vivo.

VAS2870 and VAS3947. The NOX inhibitor VAS2870 is a triazolo pyrimidine (Fig. 3) that was developed by the company Vasopharm $\mathrm{GmbH}$ in a screening approach for NOX2 inhibitors $(52,165)$. The close derivative VAS3947 is slightly improved for solubility but shows a similar NOX inhibition profile (Fig. 3) $(3,181)$. For VAS2870, only $\mathrm{IC}_{50}$ values for NOX2 inhibition were published $(52,55)$, but it was also shown that NOX4 and NOX5 activity was inhibited by the compound $(3,88)$. VAS3947 showed $\mathrm{IC}_{50}$ values around $10 \mu M$ for NOX1, NOX2, and NOX4 in cell-free assays and no inhibition of xanthine oxidase or eNOS (181). The mechanism of NOX2 inhibition seems to be inhibition of the active complex assembly as shown in an assay using a semi-recombinant system (52). In contrast to other agents,

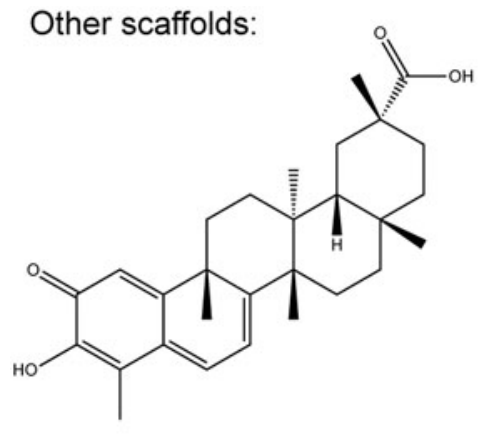

Celastrol<smiles>CC1=CCC2C(C)(C)CCC[C@]2(C)[C@]12CC[C@@](C)(CC(=O)O)O2</smiles>

Grindelic acid<smiles>CC(=O)c1ccc2c(c1)Nc1ccccc1S2</smiles>

ML171<smiles>CC(=O)OC(CCCCc1ccc(C)c(O)c1)CCc1ccc(O)c(O)c1</smiles>

FIG. 4. NOX inhibitor structures with different scaffolds. ML171 is a planar phenothiazine; Celastrol is a triterpene isolated from the plant Tripterygium wilfordii Hook $\mathrm{F}$; Grindelic acid is a diterpenoid isolated from the plant Grindelia integrifolia; and ACD 084 has a diarylheptanoid structure. 
VAS2870 only inhibited NOX2 activity in this assay when added before the induction of NOX2 active complex assembly (3) but not when added after complex assembly (3, 55). Notably, VAS2870 did not interfere with the translocation of $\mathrm{p} 47^{\text {phox }}(55)$. While this concept can be adapted easily for NOX1, the inhibition of NOX4 and NOX5 may be explained by the inhibition of an intra-molecular interaction of different domains of the enzymes (3) (illustrated in Fig. 2). Unfortunately, the poor solubility and lack of pharmacokinetic and specificity data for these substances limit their in vivo use. Recently, a potential off-target effect was reported: VAS2870 thioalkylated cysteine residues in the ryanodine receptor $\mathrm{Ca}^{2+}$ channel (RyR1) and $\mathrm{GSH}$ in vitro (167). Further analyses are required to find out whether this mechanism can be translated to the in vivo situation or be observed in the presence of physiological concentrations of GSH.

S17834. The polyphenol S17834 (Fig. 5) was developed by Servier and proposed to inhibit NOX enzymes based on the inhibition of superoxide formation in human umbilical vein endothelial cells (HUVECs) membranes. As reported, it neither scavenges superoxide nor inhibits xanthine oxidase or eNOS (27). Unfortunately, S17834 has not been further characterized with regard to its NOX isoform selectivity. However, it can be assumed that NOX2 and/or NOX4 are inhibited, as these are the main NOX isoforms expressed in HUVECs (157). Although no pharmacokinetic or safety data have been published, mouse studies suggest satisfying oral bioavailability and safety profiles $(27,96,138,187)$. These studies also revealed that $\mathrm{S} 17834$ activates adenosine<smiles>CC1=CC(=O)c2c(O)cccc2C(=O)C1=O</smiles><smiles>C=CCc1c(-c2cc(=O)c3c(O)c(CC=C)c(O)c(CC=C)c3o2)ccc(OC)c1O</smiles>

FIG. 5. Quinoid structures. The suggested NOX inhibitors S17834 and the phenantridinone group inhibitors are polyphenols with quinoid structures similar to the antioxidant plumbagin. monophosphate-activated protein kinase (AMPK) more potently than it inhibits NOX (187). Although a contribution of the NOX inhibition capabilities cannot be ruled out, the beneficial effects of S17834 in animal models of diabetes and atherosclerosis are mainly attributed to the activation of AMPK (96, 138, 183, 187).

Fulvene-5. Fulvene-5 (Fig. 3) inhibits NOX2 and NOX4mediated ROS production at $5 \mu M$ concentration by $40 \%$ in a cellular assay (15). Neither the selectivity of this compound for other NOX isoforms, potential direct ROS-scavenging effects, nor inhibition of other flavoproteins was analyzed. Fulvenes are highly water soluble, but no pharmacokinetic data and safety profiles have been reported.

Triphenylmethane derivatives. The triphenylmethane derivatives Brilliant green, Gentian violet, and Imipramin blue (Fig. 6) were examined for NOX inhibition because of structural similarity to diphenyl iodonium $(117,134)$, a weak flavoprotein inhibitor compared with its derivative DPI (own observation). All three compounds were shown to inhibit NOX4 in cellular assays in different concentrations. Brilliant green and Gentian violet were additionally tested for NOX2 inhibition. Brilliant green showed a high potency and some selectivity for NOX2 compared with NOX4, while Gentian violet inhibited both NOX isoforms with a comparably low potency (134). Imipramin blue inhibited NOX4-derived ROS generation by $\sim 50 \%$ at $5 \mu M$ (117). However, no concentration response curves and $\mathrm{IC}_{50}$ values were reported, and unspecific effects such as direct ROS-scavenging properties or inhibition of other flavoproteins were not assessed. Thus, such actions cannot be excluded. In particular, the latter would be essential due to the compounds' structural similarity to diphenyl iodonium. Since the cationic character of these compounds might hinder membrane penetration, they may interfere with extracellular domains of NOX (Fig. 2). Nevertheless, Gentian violet is FDA approved for topical applications as an antiseptic for humans, and some toxicity data were determined for Imipramin blue (117). While this might enable in vivo proof-of-concept studies for the respective indications, the unclear specificity and NOX isoform selectivity does not enable linking the effects of these compounds to NOX enzymes.

\section{Triphenylmethane derivatives:}

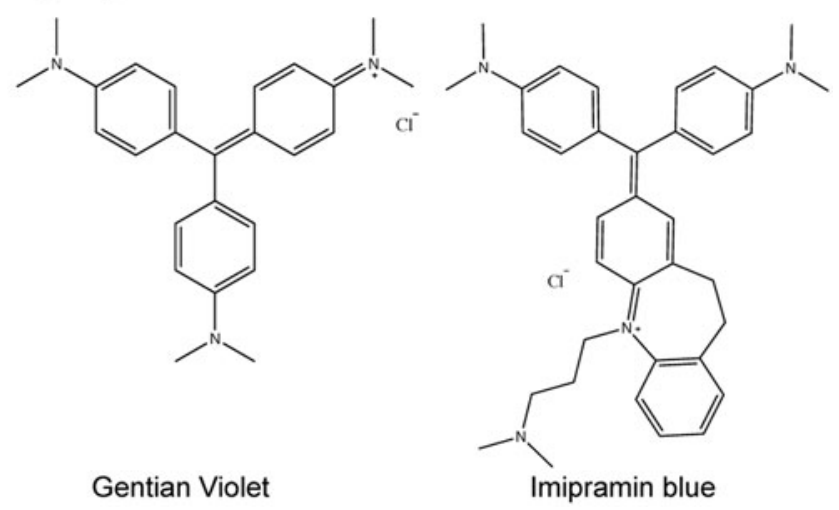

FIG. 6. Triphenylmethane derivatives. Gentian violet and Imipramin blue are planar cations with dimetylaniline side chains. 
Diarylheptanoids. Kofler et al. screened a selection of active compounds from edible plants to search for NOX4 inhibitors (89). They identified diarylheptanoid structures with four-substituted phenolic structures as the main structural feature for NOX inhibition. One of these compounds ACD 084 (Fig. 4) inhibited NOX4 with $\mathrm{IC}_{50}$ values of $3 \mu \mathrm{M}$, but it did not inhibit NOX2 or NOX5. Three similar diarylheptanoids not only showed higher potencies for NOX4 but also inhibited NOX2. While none of the mentioned compounds directly scavenged ROS, the effect on flavoproteins such as xanthine oxidase or eNOS was not analyzed. In addition, assessing a potential NOX1 inhibition by these compounds would have been important, particularly as another described potent NOX4 inhibitor class, GKT compounds, typically inhibits NOX1 and NOX4 with the same potencies $(5,92)$. This may indicate that it is difficult to obtain inhibitors with selectivity for NOX1 or NOX4. No data on the compounds' mechanism of actions have been published. However, ACD084 inhibited ROS production of the purified NOX4 dehydrogenase domain. This implies interference with FAD or NADPH binding as the mechanism of action, which is most likely not only specific for NOX4 but might also affect other NOX isoforms and other enzymes containing FAD or NADPH. The substances fulfil Lipinski's rule of five for drug-like molecules (97), and ACD084 seems to have a promising ADME profile (89).

Grindelic acid. The same screen resulting in diarylheptanoids also identified grindelic acid (Fig. 4) as an NOX4 inhibitor $\left(\mathrm{IC}_{50} 2 \mu M\right)(89)$. Grindelic acid did not inhibit NOX2 and NOX5 and was not a direct ROS scavenger. However, similar to the heptanoids, the potential inhibition of NOX1 or other flavoprotein remains to be determined. Grindelic acid's mechanism of action is unknown, but it inhibited neither ROS in a cell-free membrane-based NOX4 assay nor from the purified NOX4 dehydrogenase domain. Similar to ACD 084, it seems to have promising ADME properties. Taken together, the diarylheptanoids and grindelic acid need further validation with regard to NOX specificity and selectivity. Nevertheless, these compounds may contribute to our understanding of the structural features of NOX inhibition.

Phenantridinones and flavonoids. Phenantridinones (Fig. 5) and flavonoids were identified as potent inhibitors of NOX4 in a cell-based screening of $\sim 1000$ compounds (20). The most active compounds of the tested phenantridinone derivatives exhibited $\mathrm{IC}_{50}$ values around $200-600 \mathrm{nM}$. They neither reduced cell viability nor acted as a direct hydrogen peroxide scavenger. However, no further determination of the compounds' NOX isoform selectivity or flavoprotein inhibition potential is reported. The authors also described several flavonoids as potent NOX4 inhibitors, which are not scavenging hydrogen peroxide. However, one of the tested flavonoids was found to be an intrinsic antioxidant. Thus, these compounds should be used with caution. Flavonoids have a long history as antioxidants scavenging free radicals, lipid peroxides, and peroxynitrite $(136,147)$. Thus, although for example Quercetin [compound 7a in Borbely et al. (20)] does not seem to scavenge hydrogen peroxide according to this publication, one needs to consider the large body of literature stating antioxidant activity for this compound [reviewed in ref. (69)]. This underlines that special care should be taken to validate potential NOX inhibitors, especially natural compounds, which often show pleiotropic and direct antioxidant effects. In this regard, also off-target screens for identified compounds would be required before they could be used as reliable tools for in vivo proof-of-concept studies on NOX enzymes. Nevertheless, the authors used the structural properties of the identified NOX4 inhibitors to construct a pharmacophore model, which might help design and synthesize new NOX inhibitors, although most likely with limited NOX isoform selectivity.

Shionogi I and II. The pharmaceutical company Shionogi and Co Ltd. patented pyrazolo pyrimidine derivatives (Fig. 3) as NOX inhibitors. They claimed that this class inhibits NADPH oxidase activity in bovine aortic membrane fractions as well as in vivo in neutrophils and blood vessels (77, 162). From the inhibition of ROS release from neutrophils, the inhibition of NOX2 could be concluded, which was, indeed, recently confirmed (55). However, the authors also reported that these compounds are not direct NOX inhibitors but rather inhibit protein kinase $\mathrm{C}$, which induces NOX2 complex assembly via phosphorylation and membrane translocation of $\mathrm{p} 47^{\text {phox }}$. Thus, these compounds do not fulfil the requirements of direct NADPH oxidase inhibitors.

Ebselen. Smith et al. identified ebselen (Fig. 3) and derivatives as potent NOX2 inhibitors using an innovative approach: a recombinant protein encompassing the tandem $\mathrm{SH} 3$ domain of $\mathrm{p} 47^{\text {phox }}$ linked to a proline-rich $\mathrm{p} 22^{\text {phox }}$ peptide. This enabled them to assay direct binding of the two NADPH oxidase binding partners, $\mathrm{p} 47^{\text {phox }}$ and p $22^{\text {phox }}$ (Fig. 2) (164). It was the first published fully recombinant assay used for NOX inhibitor screening purposes (12). Hits were validated in cell-free NOX2 assays and cellular assays for NOX1, NOX2, NOX4, and NOX5. Several derivatives were used to gain insights into SAR of NOX inhibition. None of the tested compounds exhibited significant activity on NOX4. The majority of the active compounds showed selectivity for NOX1 and NOX2 compared with NOX5. One compound (JM-77b) exhibited promising NOX2 selectivity. Ebselen itself was among the most potent derivatives inhibiting NOX1, NOX2 and NOX5 with a similar potency $\left(\mathrm{IC}_{50}\right.$ values 150-700 $\mathrm{n} M$ ). It neither influenced xanthine oxidase activity nor scavenged hydrogen peroxide (see Table 1). Interestingly, the concentration of ebselen that is required for the inhibition of NOX1 and NOX2 in cellular assays is magnitudes lower than the concentrations required for the longknown action of ebselen as a glutathione peroxidase mimetic at concentrations around $10 \mu M(116)$. However, ebselen also is a potent peroxynitrite scavenger in vitro (concentration with $50 \%$ of the maximal effect $\left[\mathrm{EC}_{50}\right]$ of $\left.150 \mathrm{nM}\right)(22)$ and a moderate eNOS inhibitor in endothelial homogenates $\left(\mathrm{IC}_{50}\right.$ $8.5 \mu M)$ (188). This might complicate the interpretation of results from in vivo studies obtained with ebselen if used as an NOX inhibitor. An advantage is that ebselen is orally available and that its safety profile enabled clinical development up to phase III for the treatment of cerebral ischemia injury (109, 184). Nevertheless, the drug was never brought to the market.

Celastrol. Plant extracts from Thunder God Vine (Tripterygium wilfordii Hook F.) are used in Traditional Chinese 
Medicine to treat states of chronic inflammation. Celastrol (Fig. 4), one of the active compounds isolated from this plant, was identified to inhibit NOX2 in neutrophils. A thorough characterization of its NOX enzyme inhibition profile showed a slight selectivity for NOX1 $\left(\mathrm{IC}_{50} 0.41 \mu M\right)$ and $\mathrm{NOX} 2\left(\mathrm{IC}_{50}\right.$ $0.59 \mu M)$ compared with NOX4 $\left(\mathrm{IC}_{50} 2.79 \mu M\right)$ and NOX5 $\left(\mathrm{IC}_{50} 3.13 \mu M\right)$ in live cell assays. It also inhibited NOX2 $\left(\mathrm{IC}_{50} 1.24 \mu M\right)$ and NOX5 ( $\left.\mathrm{IC}_{50} 8.4 \mu M\right)$ in cell-free assays (76). The authors experimentally linked this selectivity to a mechanism of NOX inhibition with Celastrol binding to $\mathrm{p} 47^{\text {phox }}$ and disrupting the binding of $\mathrm{p} 47^{\text {phox }}$ to $\mathrm{p} 22^{\text {phox }}$. Interestingly, NOX4 and NOX5, which act independent of the classical organizer and activator binding proteins, are also inhibited. This suggests a more complicated mechanism of action. However, Celastrol shows a broad variety of effects and targets, such as the inhibition of topoisomerase II (119) or proteasomes (185). It is also known to covalently bind to cysteine residues [reviewed in ref. (148)]. These effects might complicate the interpretation of in vivo results obtained with Celastrol when used as an NADPH oxidase inhibitor.

Perhexiline. Perhexiline is a prophylactic anti-anginal agent that is mainly prescribed in New Zealand and Australia. Mechanistically, it was suggested to inhibit carnitine palmitoyl transferase-1 (86), resulting in a shift in myocardial energy usage from fatty acid to glucose metabolism. However, a part of its beneficial effects was also attributed to the inhibition of NOX2 in neutrophils $\left(\mathrm{IC}_{50} 1.5-3.6 \mu M\right)$ as well as in different cardiovascular tissues and cells (85). A later study confirmed the inhibition of NOX2 in neutrophils and in an assay measuring purified semi-recombinant NOX2 activity $\left(\mathrm{IC}_{50} 13.2 \mu M\right)$. Xanthine oxidase was not inhibited, and superoxide was not directly scavenged (55). This indicates direct NOX2 inhibition. However, effects on other NOX isoforms have not yet been published. Since perhexiline is an approved drug, its use in animal studies should be straightforward. However, it will be difficult to attribute results obtained in in vivo experiments to certain actions of perhexiline.

\section{Biologicals As NADPH Oxidase Inhibitors}

Biologicals as drugs include activity regulating peptides and therapeutic antibodies. The situation regarding specific antibodies against the different NOX isoforms is unsatisfying (3). So far, only a few antibodies with a suggested capacity to inhibit NOX2 (24) or NOX4 (189) were published, but they have neither been used as biologicals in experiments, nor have they been fully validated against other NOX isoforms. Peptides as drugs or inhibitors face the major limitation not only of potentially causing antigenic responses and exhibiting poor in vivo stability, but also of not being able to penetrate through cell membranes. The screening of larger peptide libraries or peptide walking along the sequence of the respective proteins in the search for modifiers of enzymes, therefore, relies on simple reproducible cell-free assays. In case of the NAPDH oxidase enzyme family, such an assay only exists for NOX2 [reviewed in ref. (40)]. Several NOX2derived peptides have been created and used to analyze the mechanisms of NOX2 activation (49). Some of these inhibited NOX2 activity. Especially peptides targeting the FAD and NADPH binding domains of NOX2 showed inhibitory effects. However, they are most likely not selective for NOX2, as all NOX isoforms show homologous FAD and NADPH binding sites (39). This might explain why only three NOX peptides have been linked to tat peptides, an HIV trans-activator protein that enables cell membrane penetration. One of these peptides is a part of the rac binding domain of NOX2 and inhibits its activity in intact neutrophils (83). However, this rac binding site is also present in NOX1 and NOX3, and, therefore, this peptide might inhibit not only NOX2 but also the other NOX isoforms. In addition, rac GTPases interact with a plethora of proteins. Thus, other unspecific effects are not unlikely. Another peptide, resembling a phosphorylation site required for the activation of $\mathrm{p} 47^{\text {phox }}$, was found to inhibit NOX2 activity in neutrophils by interference with the assembly to an active complex (41). In a similar approach, very recently, a peptide termed NOXA1ds was designed and shown to inhibit NOX1 activity (143). It was also shown that NOX4 activity could not be inhibited with specific peptides against its C-terminal tail, its B-loop, or the N-terminal tail of $\mathrm{p} 22^{\text {phox }}(37,100)$. To our knowledge, no attempts to find peptides directed against NOX3, NOX5, or DUOX1 and DUOX2 have been published. The only NOX-derived peptide, which was examined and extensively used, is NOX2 docking sequence (NOX2ds)-tat.

\section{NOX2ds-tat}

The first rationally designed biological NOX inhibitor is the 18-amino-acid peptide NOX2ds-tat (originally named gp91ds-tat). The peptide contains a nine-amino-acid sequence of the NOX2 intracellular B-loop that binds the NOX organizer protein $\mathrm{p} 47^{\text {phox }}$, thereby preventing assembly of the active NOX2 complex (74, 99, 133, 145, 194, 195) (Fig. 2). This B-loop sequence of NOX2 shows high homology with the B-loop sequences of NOX1 and NOX4. Despite this, it was recently shown that NOX2ds-tat, indeed, is selective for NOX2 compared with NOX1 and NOX4 (36). However, this proof is based on a reconstituted cell-free assay. Therefore, the inhibition of NOX1 or NOX4 in vivo in the presence of all activators and potential co-factors, which might not even have yet been discovered, cannot be excluded. Cell permeability is conferred by linking a nine-amino-acid tat peptide from the human immunodeficiency virus to the peptide. Although the tat peptide was shown to localize to the cytoplasm of neutrophils (35), NOX2ds-tat inhibited superoxide formation released by intact neutrophils only by $35 \%$; while it inhibited $80 \%$ of superoxide generated in cell-free assays (145) with an $\mathrm{IC}_{50}$ of $0.74 \mu M$ (36). Still, NOX2ds-tat was shown to be effective in several in vivo animal models, either applied intravenously or expressed via adenoviral infection, indicating that it reaches its destination $(74,99,133,194$, 195). To rule out effects caused by the tat peptide itself (25), scrambled nine-amino-acid peptide sequences linked to the tat peptide were used as controls in most of the studies (74, $133,145,194)$. In summary, NOX2ds-tat is a good tool that could be used to investigate the role of NOX in diseases, at least in acute situations.

\section{NOXA1ds}

The first peptide inhibitor of NOX1 activity was developed in a similar approach as the one that led to the identification of NOX2ds-tat (143). This peptide contains the 11-amino-acid sequence of the docking sequence of NOXA1 to NOX1. It 


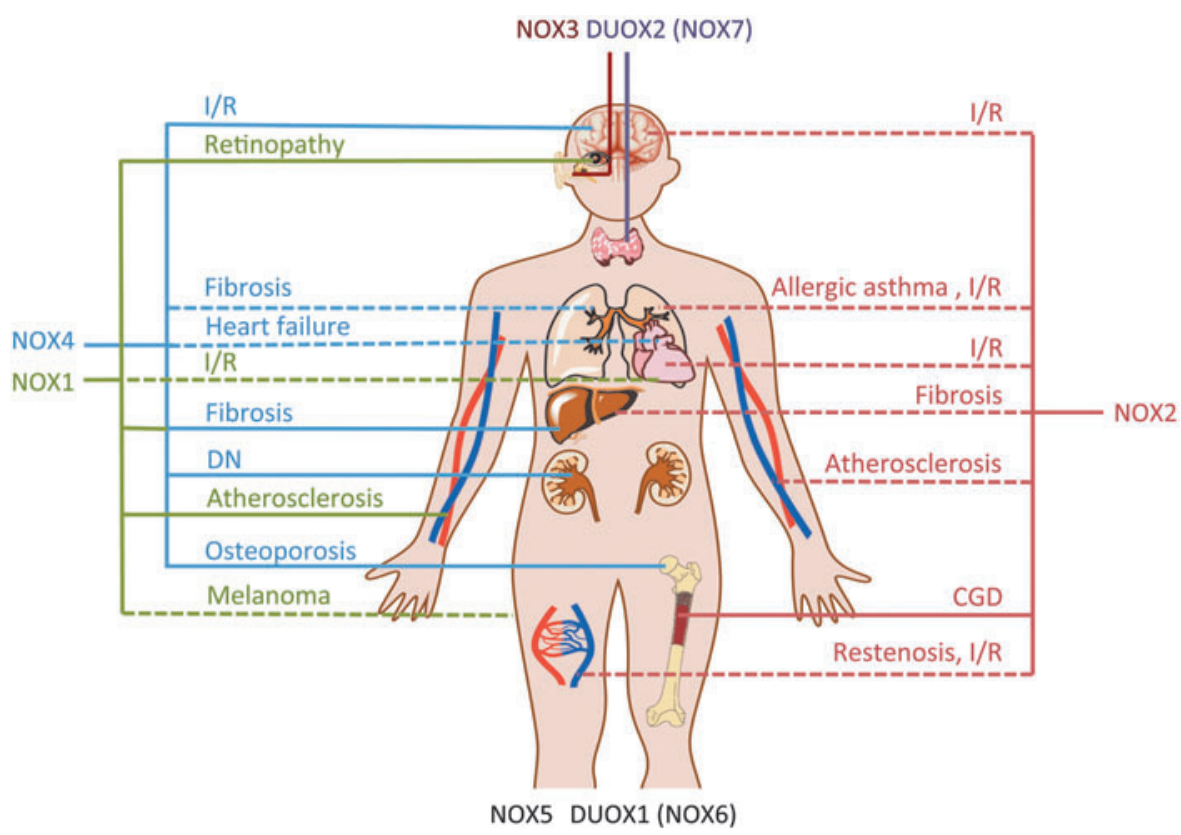

FIG. 7. NOX enzymes as validated therapeutic targets. The validation status of NOX1-7 is presented based on partial validation of the mentioned disease model in knockout animals or by using NOX inhibitors (dashed lines), or-for full validation-based on both knockout animals and NOX inhibition or knowledge on mutations leading to human disease (full lines). Knockout mice and inhibition studies strongly suggested NOX1 (green lines) as a therapeutic target in diabetic atherosclerosis (64), ischemic retinopathy (179), and-in interaction with NOX4-liver fibrosis (5, 79, 129). A role in melanoma progression and tumor angiogenesis (54) needs to be confirmed in NOX1 knockout mice, while a role of NOX1 in heart I/R injury (21) needs to be confirmed by pharmacologic inhibition of NOX1. NOX2 (red lines) is suggested to be involved in almost every animal disease model, especially involving inflammatory components. The involvement in CGD is based on human disease and, therefore, validated. A likely role of NOX2 in atherosclerosis, endothelial dysfunction, and restenosis after arterial injury is based on both NOX2 knockout animals $(30,81)$ and studies with the NOX2ds-tat peptide $(46$, $74,177,194)$. NOX2 should, therefore, be further considered a target for atherosclerosis and restenosis after arterial injury. A minor role for NOX2 was found in I/R injury of several organs, including the brain [reviewed in ref. (140)], lung (178), and heart $(51,101)$, but this is currently insufficiently validated. The role of NOX2 in liver fibrosis (129) and allergic asthma (6) is awaiting confirmation with specific NOX2 inhibitors. NOX3's (brown line) physiological role in the inner ear can be considered fully validated in the mouse model, as NOX3 specific inhibition prevented cisplatin-induced hearing loss. NOX4 (blue lines) is a valid therapeutic target for stroke (88), diabetic nephropathy (78), liver fibrosis (5, 79), and osteoporosis (60), at least in mice. The validation of NOX4's role in lung fibrosis and heart failure needs to be confirmed using specific NOX inhibitors and knockout animals in a relevant model. For NOX5, a role in spermatozoa motility was suggested based on the inhibition with GKT136901 (118). DUOX1/NOX6 knockout animals do not show an obvious phenotype, but roles in the bladder (45) or in the lung host defence system were suggested (173). Dysfunctional DUOX2/NOX7 (purple line) due to biallelic mutations in humans leads to severe hypothyroidism. CGD, chronic granulomatous disease; I/R, ischemia-reperfusion. To see this illustration in color, the reader is referred to the web version of this article at www.liebertpub.com/ars

was shown to bind to NOX1 and to prevent assembly of the active NOX1 complex (143). The inventors chose an aminoacid-sequence that markedly differs from similar sequences in NOX2 to provide NOX isoform selectivity. Conclusively, they showed that the peptide does not inhibit NOX2, NOX4, or NOX5 in assays using lysates of transfected cells (143). Further, no inhibition of xanthine oxidase or direct superoxide scavenging by NOXA1ds was observed. However, as mentioned earlier for NOX2ds-tat, the inhibition of different NOX isoforms in living cells with intact signaling pathways and potential activating factors was not determined. Although the peptide was shown to penetrate through cellular membranes, its in vivo efficacy remains to be determined.

\section{NOX Isoforms-Are They Really Therapeutic Targets?}

ROS and NADPH oxidases as one of their main sources were suggested to be involved in many diseases. However, for a long time, a validated physiological function could only be found for NOX2 and DUOX2 based on mutations in humans or mice leaving a dysfunctional protein and therefore leading to chronic granulomatous disease (CGD) or severe hypothyroidism, respectively $(47,80,113)$. The role of the other NADPH oxidase isoforms in health and disease were for a long time - and for NOX5 still are-based on reported up-regulations of NOX expression levels in certain disease conditions or based on results from cultured cells. The solid validation of NADPH oxidases as potential drug targets (Fig. 7) only started with the introduction of the first NOX knockout (KO) mice. The first NOX KO mice, NOX2 KO, was published in 1995 (137). It took another 10 years until a NOX1 KO mouse was published $(56,103)$. Only in 2010 , four reports of NOX4 KO mice came out, with all four using different targeting strategies $(26,88,91,190)$. In the same year, a DUOX1 KO mouse was published (45). Since NOX5 is not expressed in mice and rats, no $\mathrm{KO}$ animals exist. In case 
of the other NOX isoforms, the availability of KO mice enabled a more detailed validation of the roles of different NOX isoforms in health and disease. However, most $\mathrm{KO}$ models are constitutive. Thus, the deleted gene is already absent before the induction of a disease in a mouse model, whichwith the exception of human monogenic diseases such as CGD - does not mimic the human disease pathology. In addition, the long-term absence of the gene might trigger compensatory changes, masking the actual effect of the lacking gene product. Thus, for the validation of NOX enzymes as drug targets, not only the effect of a deletion of a NOX isoform but also the inhibition of its activity by small molecules or peptides in a disease model is required.

\section{The history of the in vivo use of novel NOX inhibitors is short}

The number of validated and largely specific NOX inhibitors that have been applied for proof-of-concept studies is limited. Although DPI and-even more-apocynin have been extensively used to inhibit NOX enzymes in numerous disease models [reviewed in refs. $(142,157)]$, they are inadequate to determine the role of NAPDH oxidases due to their unspecific effects mentioned earlier. The NOX2 inhibitory peptide NOX2ds-tat and GKT136901/GKT137831 have been used as relatively specific NOX inhibitors in vivo and, to a lesser extent, also VAS2870, Fulvene-5, and Imipramine blue.

\section{NOX1 as a therapeutic target for diabetic}

atherosclerosis, ischemic retinopathy, and liver fibrosis

NOX1 has been suggested to play a role in vascular disorders such as hypertension, atherosclerosis, and ischemic injuries, but final validation is warranted. More recently, NOX1 has been validated as a pathologic player in diabetic atherosclerosis (64). Both treatment of streptozotocin (STZ)treated apolipoprotein E (ApoE) KO mice with the NOX1/4 inhibitor GKT137831 and deletion of NOX1 in STZ-treated ApoE KO mice resulted in a profound anti-atherosclerotic effect. In contrast, the deletion of NOX4 in STZ-treated ApoE KO mice was not protective. A role of NOX1 in atherosclerosis is further supported by two other studies. The first showed decreased lesion area and macrophage infiltration, two hallmarks of atherosclerosis, in NOX1/ApoE double KO mice after high fat diet feeding compared with ApoE KO mice (160); the second showed decreased atherosclerotic lesions and cellular surface adhesion factor CD44 in ApoE KO mice treated with GKT136901 (176). Very recently, NOX1 was also validated as a therapeutic target in ischemic retinopathy (179). Using a rodent model of retinopathy of prematurity, which is a major cause of blindness caused by damage to the retinal microvasculature, retinas of NOX1 KO mice showed reduced signs of retinopathy, such as neovascularization and avascular retina. In contrast, retinas of NOX2 and NOX4 KO mice were not protected. In addition, a subcutaneous injection of the NOX1/4 inhibitor GKT137831 protected rat retinas from retinopathy when applied during the hyperoxic or during the next normoxic phase (179). This effect in post-hyperoxic rats confirms the therapeutic potential of NOX inhibition in ischemic retinopathy. With regard to ischemia-reperfusion injury in the heart, another study reported that NOX1 and NOX2 KO mice, as well as combined NOX1/NOX2 KO, but not NOX4 KO mice were pro- tected (21). Notably, no protection was seen using a permanent ischemia model. However, to validate the role of NOX1 and NOX2 in heart ischemia-reperfusion, data on the pharmalogical inhibition of these NOX isoforms is warranted. Despite a mild hypotensive phenotype of NOX1 KO mice (56), a role of NOX1 in blood pressure regulation and hypertension has not yet been fully validated. Most studies exploring a role of NOX1 in blood pressure used angiotensin II (AngII)-mediated hypertension models $(56,103)$. However, AngII infusion does not necessarily reflect the human situation of hypertension, as unphysiologically high concentrations of AngII are required to increase the blood pressure and induce end organ damage. Therefore, the proposed role of NOX1 in hypertension might not be translatable to the human situation. In addition, NOX1 deletion did not change blood pressure in a hypertension model using a transgenic mouse expressing human renin (186). No differences in blood pressure have been detected in mice treated with the NOX1/NOX4 inhibitor GKT136901 (156).

Next to cardiovascular diseases, a role of NOX1 in liver fibrosis evolved. Treatment with the NOX1/NOX4 inhibitor GKT137831 attenuated hepatic fibrosis in bile duct ligation and hepatotoxin models (5). The authors showed that NOX1 up-regulation leads to increased expression of NOX4 and suggested the inhibition of both NOX isoforms as a promising therapeutic strategy in hepatic fibrosis. The same group validated this role of NOX1 by showing attenuation in both NOX1 and NOX2 KO mice (129). The role of NOX4 in liver fibrosis was confirmed by another study showing that GKT137831 treatment and NOX4 deletion attenuated fibrosis in mice (79). Based on these results, a causal interaction between NOX1 and NOX4 seems likely in disease progression. Therefore, both isoforms represent potential therapeutic targets for these liver pathologies.

NOX1 was further suggested to mediate tumor angiogenesis after an injection of two different tumor cells into mice (54). Surprisingly, tumor angiogenesis by melanoma cells was attenuated in NOX1-deficient mice, while GKT136901 treatment decreased tumor angiogenesis and weight in the other tumor model. A more detailed analysis on the role of NOX1 in tumor angiogenesis is, therefore, required before declaring NOX1 as a validated therapeutic target for cancer. Based on observations in NOX1-deficient mice, NOX1 may also be relevant in models of neointima formation after wireinduced injury of the femoral artery (95), of neuroinflammation (34), and of hyperalgesia (73). Nevertheless, since a therapeutic branch was not explored for the latter disease models, NOX1 cannot yet be considered a validated therapeutic target for the treatment of these diseases.

\section{NOX2 inhibition-one to cure them all?}

NOX2 KO mice display an impaired immune defence against pathogens and represent a validated model of CGD (137). Therefore, complete abrogation of NOX2 activity might not be acceptable in humans. This should be kept in mind when considering the inhibition of NOX2 for therapeutic purposes. Up-regulated or overly active NOX2 has been implied in a plethora of diseases, especially diseases of the cardiovascular and cerebrovascular system [reviewed in ref. (47)]. The role of NOX2 in the innate and adaptive immune response might help explain this involvement of NOX2 in the majority of tested 
disease models. Overall, NOX2 has been linked to almost every animal disease model, with many of them involving a significant inflammatory component. The protective effects often observed by deleting NOX2 in mice may, thus, be mediated by an attenuated inflammatory response. On the inhibitory side, NOX2 is the rare exception among the NOX enzymes, as with NOX2ds-tat a selective inhibitor is available. Unfortunately, the low bioavailability of peptides limits its use for in vivo applications and potential therapeutic options in humans. Due to the large number of studies using NOX2 KO mice or the NOX2ds-tat peptide, we will focus on indications that were assessed by several groups or which were validated using both NOX2 inhibitors and $\mathrm{KO}$ mice.

NOX2 inhibition was shown to be effective in different cerebrovascular regulations and disturbances in the preventive branch by NOX2 $\mathrm{KO}$ and in the therapeutic branch by NOX2ds-tat. These indications include age-dependent neurovascular de-regulation (131), AngII-induced de-regulations in cerebral blood flow, and neurovascular coupling $(59,84)$, as well as Alzheimer's disease models, namely in amyloid precursor protein- (133) and amyloid beta peptideinduced de-regulations (132). However, in these models, NOX2ds-tat was applied via a cranial window, which almost excludes these studies as valuable proof of concepts for NOX inhibition in human therapy of these diseases. Several studies suggested a protection by deleting NOX2 in brain ischemia reperfusion injury, some by applying unspecific inhibitors such as apocynin, DPI (120), or ebselen (90) [reviewed in ref. (140)]. Next to the unspecific character of these inhibitors, the time point of application, namely pre-stroke, presents the major drawback of these studies, as this does not reflect a realistic treatment option. The role of NOX2 in stroke was partly confirmed by protection with NOX2ds-tat in rats when applied before (144) or even after ischemia reperfusion (191). In contrast, another study found no protective effect of deleting $\mathrm{NOX} 2 \mathrm{KO}$ in stroke (88). However, the protective effect of NOX2 inhibition or NOX2 deletion in these studies was rather moderate, and the studies were largely underpowered (139). In conclusion, NOX2 may play a role in stroke, but the effect is still under discussion. Therefore, at present, NOX2 cannot be considered a validated stroke target. This also holds true for many other diseases. Remarkably, the use of NOX2 $\mathrm{KO}$ animals and studies using NOX2ds-tat $(98,99,194)$ suggest that NOX2 is not involved in blood pressure regulation or hypertension in mice. In contrast, a role of NOX2 in hypertension in spontaneously hypertensive rats (SHRs) based on NOX2 inhibition by NOX2ds-tat was suggested $(158,195)$. Thus, NOX2-derived ROS might be involved in baroreceptor reflex regulation in these rats (158). However, a further analysis is required to clarify the precise role of NOX2 in SHR and in blood pressure regulation in different species. A role of NOX2 in vascular disorders such as restenosis after arterial injury $(30,46$, $74,177)$, endothelial dysfunction, and atherosclerosis $(11,81$, $98,99,145,175,194)$ was suggested based on experiments with NOX2 KO models and by the inhibition of NOX2 with NOX2ds-tat. However, the respective various studies used slightly different disease models. Accordingly, a direct comparison is not straightforward. Therefore, NOX2 should not be considered a fully validated target for these diseases. Furthermore, chronic treatment with NOX2 inhibitors would always carry the risk of impairment of the immune system.
Diabetic NOX2 KO mice (STZ model), for example, showed increased susceptibility to Gram-negative infections and died at 20 weeks after diabetes induction unless treated with antibiotics (64). Importantly, even a protective role of NOX2derived ROS in the severity of autoimmune diseases such as rheumatoid arthritis has been suggested (149).

\section{NOX3 - a target candidate for cisplatin-induced hearing loss}

Based on a mutant mouse study, a functional role of NOX3 in otoconia formation in the inner ear was described (128). NOX3 was also suggested to be the main source of ROS in cisplatin-induced hearing loss $(7,115)$. This effect was prevented by in vivo application of NOX3 small interfering RNA (siRNA) into the rat ear (114) and of a small molecule that inhibited NOX3 mRNA expression after cisplatin treatment (161). With the exception of ML171 ( $\mathrm{IC}_{50}$ of $\left.7.5 \mu M\right)$, none of the novel NOX inhibitors has been tested for its ability to inhibit NOX3. It would be interesting to know whether the other inhibitors attenuate NOX3 activity. If so, their use may provide a final proof of concept for a critical role of NOX3 in cisplatin-induced hearing loss.

\section{NOX4 as a therapeutic target for ischemic stroke, diabetic nephropathy, and osteoporosis}

With four different KO mice and several proposed inhibitors, NOX4 seems to be the best validated drug target among the NOX isoforms. NOX4 KO or an intrathecal injection of the NOX inhibitor VAS2870 significantly reduced mortality and infarct size and improved neurological outcome in a mouse brain ischemia-reperfusion model (88). A role of NOX4 in diabetic nephropathy has already been suggested in 2005 (61), and the GKT inhibitors are developed by GenKyoTex for this indication since several years. Therefore, the validation of NOX4 as a target in diabetic nephropathy came rather late. Diabetic nephropathy was significantly reduced in terms of albuminuria, collagen IV accumulation in glomeruli, fibronectin accumulation, and vascular endothelial growth factor expression in NOX4 KO and wild-type mice treated with GKT137831 in an STZ model of insulin-independent diabetes (78). Along with an earlier study conducted in $\mathrm{db} / \mathrm{db}$ mice that already suggested a role for diabetic nephropathy based on results obtained with GKT136901 (155), NOX4 can be considered a validated target for diabetic nephropathy, at least in mice. Recently, NOX4 was validated as another therapeutic target. Both inducible genetic KO of NOX4 and NOX1/4 inhibition with an NOX inhibitor by GenKyoTex attenuated bone loss in an ovariectomy model of murine osteoporosis (60). The effect of pharmacological NOX inhibition on bone loss in this mouse model was less pronounced than the effect of the gold standard therapeutic bisphosphonate (60). Nevertheless, NOX4 KO mice showed significantly increased bone density, and higher NOX4 protein levels have even been detected in bones of human osteoporosis patients. Furthermore, NOX4 was suggested to be the main ROS source in fibrotic diseases of different organs, including the lung (68), liver (10), and heart (38). As already discussed in the section on NOX1, the role of NOX4 in hepatic fibrosis was reported in NOX4 KO mice and confirmed by GKT137831 treatment $(5,79)$. Surprisingly, NOX4 is not fully validated as a therapeutic target in pulmonary fibrosis, although GKT137831 was granted orphan 
drug status for the treatment of idiopathic pulmonary fibrosis. While genetic deletion in a NOX4 KO mouse (26) or genetic silencing using siRNA versus NOX4 in vivo (68) improved bleomycin-induced pulmonary fibrosis, the in vivo application of a pharmacological NOX4 inhibitor for the treatment has not been reported. However, the authors described a reduction of the collagen content in lungs of bleomycin-treated mice after intratracheal application of a close analogue of GKT137831. However, histological data clearly showing fibrosis in these lungs are not presented in this publication (53). In general, the bleomycin model only enables limited statements on drug efficacies against lung fibrosis. Only compounds that prevent or stop progression of fibrosis have the potential to be translated into the clinic (110). Importantly, fibrosis does not ordinarily progress in this model (153). Another role for NOX4 in pulmonary vessels was suggested, as GKT137831 treatment prevented hypoxia-induced right ventricle hypertrophy, thereby attenuating pulmonary hypertension (65). However, an involvement of NOX4 in pulmonary hypertension still awaits confirmation in NOX4 KO animals. The role of NOX4 in heart failure is discussed controversially. A cardiac-specific NOX4 KO mouse was protected from heart failure that developed after thoracic aortic banding (91), a rather severe model of heart failure progression. In contrast, a constitutive NOX4 KO mouse showed more pronounced heart failure after abdominal aortic banding (190), a comparably mild model of heart failure. This suggests that NOX4 is beneficial in chronic heart failure by mediating angiogenesis, an effect that has also been shown in hindlimb ischemia (152). In contrast, acute activation of NOX4 in a severe heart failure model may result in toxic ROS concentrations. Other proposed pathological roles of NOX4 include the progression of tumor invasion of glioblastoma cells into healthy tissue and the growth of hemangiomas. While the first could be inhibited with imipramine blue (117), the second could be inhibited with Fulvene-5 (15). However, the unclear isoform specificity of these compounds does not enable any attribution of these functions to NOX4.

In conclusion, we recommend the use of NOX KO animals in parallel to inhibitors in order to validate NOX4 as a therapeutic target for any diseases. Finally, NOX4 inhibition was suggested as therapy for the treatment of neuropathic pain (82). The effectiveness of preventions was shown using NOX4 KO animals. However, again, inhibitor studies are required to validate $\mathrm{NOX} 4$ as a therapeutic target for neuropathic pain.

\section{Is NOX5 a neglected therapeutic target?}

Since NOX5 is not expressed in mice and rats, its role is less clear than the role of any of the other NOX isoforms. Since KO strategies in larger animals, such as rabbits, have only recently become available and are expensive, the use of selective NOX5 inhibitors might be a more promising approach while analyzing its role in larger animals. So far, only GKT compounds were tested or shown to exhibit potent inhibition of NOX5 in a cellular system (5). Since NOX5 likely is the only NOX isoform in human spermatozoa, the inhibition of ROS formation by GKT137831 in spermatozoa was attributed to NOX5. As a first hint on a physiological role of NOX5, it was shown that NOX5 in- hibition decreased spermatozoa motility (118). However, the knowledge on NOX5 is still too limited to consider it as a therapeutic target for any disease.

\section{DUOX1/NOX6 and DUOX2/NOX7-only relevant for hypothyroidism?}

The physiological and pathophysiological roles of DUOX1 are widely unknown. A recently published DUOX1 KO mouse showed no obvious phenotype (45). However, a role of DUOX1-derived hydrogen peroxide for pressure responses in the urinary bladder was suggested (45). Dysfunctional DUOX2 leads to severe hypothyroidism in humans and mice. To our knowledge, nothing is known about the dysregulation of DUOX2 in hyperthyroidism, which would represent the only imaginable therapeutic use for a DUOX2 inhibitor at this time. In addition, no selective inhibitors for DUOX1 or DUOX2 have been identified, and none of the developed NOX inhibitors have been tested on their abilities to inhibit DUOX1 or DUOX2. Finally, one publication reported the inhibition of DUOX-derived hydrogen peroxide by VAS2870 in a zebra fish woundhealing model (122). However, whether there is a role for DUOX1 (NOX6) or DUOX2 (NOX7) in higher animals remains to be determined.

\section{Future NOX Inhibitors}

\section{Need for future of small-molecule NOX inhibitors}

Until now, the role of NOX isoforms in disease has only been validated in animals for NOX1 in diabetic atherosclerosis, liver fibrosis, and ischemic retinopathy; for NOX2 in CGD and probably inflammatory diseases; for NOX4 in stroke, diabetic nephropathy, osteoporosis, and liver fibrosis; and for DUOX2 in hypothyroidism. However, for all other suggested diseases, the final proof for a role of NOX isoforms is lacking. Apart from clear physiological roles of NOX2 and DUOX2, we still do not know exactly what physiological functions the other NOX isoforms fulfil, neither in mice let alone in humans. A role of NOX4 in hypoxia-induced angiogenesis seems likely (152), NOX5-derived superoxide might be responsible for sperm motility (118), and DUOX1 might be involved in pathogen defence in the lung (173) as well as play a role in bladder contractions (45). The currently available NOX inhibitors lack the clear NOX isoform selectivity that would be required to exclusively rely on data obtained with inhibitors. Therefore, for complete validation of a physiological or pathophysiological role of a specific NOX isoform and its validation as a drug target, both need to be studied: NOX KO animals and NOX inhibitors in parallel and in combination.

Although clearly isoform selective inhibitors might not be required for acute treatment of diseases such as stroke, most other indications of NOX inhibition, currently liver fibrosis, osteoporosis, diabetic atherosclerosis, and diabetic nephropathy, would require chronic treatment with NOXinhibiting drugs. Since the physiological functions of most NOX isoforms are still unknown, unpredictable side effects of non-selective NOX inhibition in long-term treatment cannot be ruled out. In conclusion, for both, validation of the role of NOX isoforms in health and disease and for development into drugs against these diseases, future NOX inhibitors with clear isoform selectivities are required. In addition, oral bioavailability would be desired. 


\section{Potential for novel biologicals-therapeutic antibodies}

The field of therapeutic antibodies for use in humans is flourishing and provides new exciting therapeutic options. Currently, therapies using these novel biologicals are mainly available for the treatment of cancer, autoimmunity, and inflammatory diseases (94). One of their main strengths is their high potential for target specificity combined with a low toxicity. Therefore, therapeutic antibodies also have a high prospective for treating diseases that involve certain NOX isoforms. An antibody that inhibits NOX isoform activity would have to be directed against extracellular regions of NOX, and it would have to be generated in large amounts in a reproducible and high quality. However, so far, hardly any specific antibodies against the different NOX isoforms exist (3), with NOX2 being the exception. Here, four promising monoclonal antibodies targeting the extracellular loops of NOX2 have been created and shown to inhibit NOX2 activity in living neutrophils and a reconstituted cell-free assay (24). As soon as the NOX antibody dilemma for other NOX isoforms is solved, the road for therapeutic antibodies may be paved. Recently, a first step in this direction was the development of a monoclonal antibody against the extracellular Eloop of NOX4 (189). Although this antibody was not able to inhibit NOX4 activity in a cell-free assay (189), it moderately inhibited NOX4-derived hydrogen peroxide production in transfected cells that expressed NOX4 in the plasma membrane (169). However, none of the monoclonal antibodies against NOX2 or NOX4 are freely available yet, and they would still need to be validated in NOX KO models and to be tested against other NOX isoforms. In conclusion, this progress may present a first step in the direction of therapeutic antibodies against NADPH oxidases.

\section{Conclusions}

Much information is already available suggesting pathologically relevant implications of NOX isoforms in several diseases. However, a complete validation of the role of individual NOX isoforms in diseases will require further studies. These should show not only beneficial effects in KO animals of the respective NOX isoform but also in parallel proof of the therapeutic potential by attenuation of the disease using a specific inhibitor in a given disease model. Ideally, the role of other NOX isoforms in the respective model should be excluded by using other NOX KO animals.

Based on specificity for NOX proteins, isoform selectivity, and toxicity of currently available NOX inhibitors, we recommend the GKT compounds and NOX2ds-tat for NOX1/4 and NOX2 inhibition, respectively. For additional validation, ML171 and the VAS compounds are a good choice. However, in future, fully isoform selective NOX inhibitors with favorable toxicity and bioavailability are still required. Biologicals, such as peptides and therapeutic antibodies, have provided the potential for specific, selective, and effective therapeutic options for the treatment of diseases that are linked to the over-activation of NOX enzymes.

\section{Acknowledgments}

The authors would like to acknowledge J.J. Rob Hermans and Tessa S. van Kempen for carefully reading this article. H.H.H.W.S. is supported by a Marie Curie International
Reintegration Grant, an ERC Advanced Investigator Grant, and the Dutch Kidney Foundation. H.H.H.W.S. chairs and $\mathrm{K}$.W. is a management committee member of the COST Action BM1203.

\section{Author Disclosure Statement}

H.H.H.W.S. declares that he holds shares in vasopharm GmbH (Würzburg, Germany), which pharmaceutically develops NADPH oxidase inhibitors. H.H.H.W.S. and K.W. are inventors of a patent (US8236809) on VAS2870 and VAS3947, which is owned by vasopharm GmbH (Würzburg, Germany). No competitive financial interests exist for S.A., K.A.R., and P.W.M.K.

\section{References}

1. Ago T, Kuroda J, Pain J, Fu C, Li H, and Sadoshima J. Upregulation of Nox4 by hypertrophic stimuli promotes apoptosis and mitochondrial dysfunction in cardiac myocytes. Circ Res 106: 1253-1264, 2010.

2. Aldieri E, Riganti C, Polimeni M, Gazzano E, Lussiana C, Campia I, and Ghigo D. Classical inhibitors of NOX NAD(P)H oxidases are not specific. Curr Drug Metab 9: 686-696, 2008.

3. Altenhöfer S, Kleikers PWM, Radermacher KA, Scheurer $\mathrm{P}$, Rob Hermans JJ, Schiffers P, Ho H, et al. The NOX toolbox: validating the role of NADPH oxidases in physiology and disease. Cell Mol Life Sci 69: 2327-2343, 2012.

4. Anilkumar N, Jose GS, Sawyer I, Santos CXC, Sand C, Brewer AC, Warren D, et al. A 28-kDa splice variant of NADPH oxidase-4 is nuclear-localized and involved in redox signaling in vascular cells. Arterioscler Thromb Vasc Biol 33: e104-e112, 2013.

5. Aoyama T, Paik Y-H, Watanabe S, Laleu B, Gaggini F, Fioraso-Cartier L, Molango S, et al. Nicotinamide adenine dinucleotide phosphate oxidase in experimental liver fibrosis: GKT137831 as a novel potential therapeutic agent. Hepatology 56: 2316-2327, 2012.

6. Banerjee ER and Henderson WR. Role of $\mathrm{T}$ cells in a gp91phox knockout murine model of acute allergic asthma. Allergy Asthma Clin Immunol 9: 6, 2013.

7. Bánfi B, Malgrange B, Knisz J, Steger K, Dubois-Dauphin $\mathrm{M}$, and Krause $\mathrm{K}-\mathrm{H}$. NOX3, a superoxide-generating NADPH oxidase of the inner ear. J Biol Chem 279: 46065-46072, 2004.

8. Bánfi B, Molnár G, Maturana A, Steger K, Hegedûs B, Demaurex $\mathrm{N}$, and Krause $\mathrm{KH}$. A $\mathrm{Ca}(2+)$-activated NADPH oxidase in testis, spleen, and lymph nodes. $J$ Biol Chem 276: 37594-37601, 2001.

9. Bánfi B, Tirone F, Durussel I, Knisz J, Moskwa P, Molnár GZ, Krause K-H, et al. Mechanism of $\mathrm{Ca} 2+$ activation of the NADPH oxidase 5 (NOX5). J Biol Chem 279: 1858318591, 2004.

10. Barnes JL and Gorin Y. Myofibroblast differentiation during fibrosis: role of $\mathrm{NAD}(\mathrm{P}) \mathrm{H}$ oxidases. Kidney Int 79: 944-956, 2011.

11. Barry-Lane PA, Patterson C, van der Merwe M, Hu Z, Holland SM, Yeh ET, and Runge MS. p47phox is required for atherosclerotic lesion progression in $\operatorname{ApoE}(-/-)$ mice. J Clin Invest 108: 1513-1522, 2001.

12. Bedard K and Jaquet V. Cell-free screening for NOX inhibitors. Chem Biol 19: 664-665, 2012. 
13. Bedard K and Krause K-H. The NOX family of ROSgenerating NADPH oxidases: physiology and pathophysiology. Physiol Rev 87: 245-313, 2007.

14. Ben Mkaddem S, Pedruzzi E, Werts C, Coant N, Bens M, Cluzeaud F, Goujon JM, et al. Heat shock protein gp96 and $\mathrm{NAD}(\mathrm{P}) \mathrm{H}$ oxidase 4 play key roles in Toll-like receptor 4-activated apoptosis during renal ischemia/ reperfusion injury. Cell Death Differ 17: 1474-1485, 2010.

15. Bhandarkar SS, Jaconi M, Fried LE, Bonner MY, Lefkove B, Govindarajan B, Perry BN, et al. Fulvene-5 potently inhibits NADPH oxidase 4 and blocks the growth of endothelial tumors in mice. J Clin Invest 119: 2359-2365, 2009.

16. Bjelakovic G, Nikolova D, Gluud LL, Simonetti RG, and Gluud C. Mortality in randomized trials of antioxidant supplements for primary and secondary prevention: systematic review and meta-analysis. JAMA 297: 842-857, 2007.

17. Block K and Gorin Y. Aiding and abetting roles of NOX oxidases in cellular transformation. Nat Rev Cancer 12: 627-637, 2012.

18. Block K, Gorin Y, and Abboud HE. Subcellular localization of Nox4 and regulation in diabetes. Proc Natl Acad Sci U S A 106: 14385-14390, 2009.

19. Borbély G, Huszár M, Varga A, Futosi K, Mócsai A, Orfi $\mathrm{L}$, Idei $\mathrm{M}$, et al. Optimization of important early AD$\mathrm{ME}(\mathrm{T})$ parameters of NADPH oxidase-4 inhibitor molecules. Med Chem 8: 174-181, 2012.

20. Borbély G, Szabadkai I, Horváth Z, Markó P, Varga Z, Breza N, Baska F, et al. Small-molecule inhibitors of NADPH oxidase 4. J Med Chem 53: 6758-6762, 2010.

21. Braunersreuther V, Montecucco F, Ashri M, Pelli G, Galan K, Frias M, Burger F, et al. Role of NADPH oxidase isoforms NOX1, NOX2 and NOX4 in myocardial ischemia/ reperfusion injury. J Mol Cell Cardiol 64: 99-107, 2013

22. Briviba K, Roussyn I, Sharov VS, and Sies H. Attenuation of oxidation and nitration reactions of peroxynitrite by selenomethionine, selenocystine and ebselen. Biochem $J$ 319 (Pt 1): 13-15, 1996.

23. Cairns B, Kim JY, Tang XN, and Yenari MA. NOX inhibitors as a therapeutic strategy for stroke and neurodegenerative disease. Curr Drug Targets 13: 199-206, 2012.

24. Campion Y, Paclet M-H, Jesaitis AJ, Marques B, Grichine A, Berthier S, Lenormand J-L, et al. New insights into the membrane topology of the phagocyte NADPH oxidase: characterization of an anti-gp91-phox conformational monoclonal antibody. Biochimie 89: 1145-1158, 2007.

25. Cardozo AK, Buchillier V, Mathieu M, Chen J, Ortis F, Ladrière L, Allaman-Pillet $\mathrm{N}$, et al. Cell-permeable peptides induce dose- and length-dependent cytotoxic effects. Biochim Biophys Acta 1768: 2222-2234, 2007.

26. Carnesecchi S, Deffert C, Donati Y, Basset O, Hinz B, Preynat-Seauve O, Guichard $\mathrm{C}$, et al. A key role for NOX4 in epithelial cell death during development of lung fibrosis. Antioxid Redox Signal 15: 607-619, 2011.

27. Cayatte AJ, Rupin A, Oliver-Krasinski J, Maitland K, Sansilvestri-Morel P, Boussard MF, Wierzbicki M, et al. S17834, a new inhibitor of cell adhesion and atherosclerosis that targets nadph oxidase. Arterioscler Thromb Vasc Biol 21: 1577-1584, 2001.

28. Chen F, Pandey D, Chadli A, Catravas JD, Chen T, and Fulton DJR. Hsp90 regulates NADPH oxidase activity and is necessary for superoxide but not hydrogen peroxide production. Antioxid Redox Signal 14: 2107-2119, 2011.

29. Chen F, Yu Y, Qian J, Wang Y, Cheng B, Dimitropoulou C, Patel $\mathrm{V}$, et al. Opposing actions of heat shock protein 90 and
70 regulate nicotinamide adenine dinucleotide phosphate oxidase stability and reactive oxygen species production. Arterioscler Thromb Vasc Biol 32: 2989-2999, 2012.

30. Chen Z, Keaney JF, Schulz E, Levison B, Shan L, Sakuma $\mathrm{M}$, Zhang $\mathrm{X}$, et al. Decreased neointimal formation in Nox2-deficient mice reveals a direct role for NADPH oxidase in the response to arterial injury. Proc Natl Acad Sci U S A 101: 13014-13019, 2004.

31. Cheng $G$ and Lambeth JD. Alternative mRNA splice forms of NOXO1: differential tissue expression and regulation of Nox1 and Nox3. Gene 356: 118-126, 2005.

32. Cheng G, Ritsick D, and Lambeth JD. Nox 3 regulation by NOXO1, p47phox, and p67phox. J Biol Chem 279: 34250-34255, 2004.

33. Cheng Y and Prusoff WH. Relationship between the inhibition constant (K1) and the concentration of inhibitor which causes 50 per cent inhibition (I50) of an enzymatic reaction. Biochem Pharmacol 22: 3099-3108, 1973.

34. Chéret C, Gervais A, Lelli A, Colin C, Amar L, Ravassard $\mathrm{P}$, Mallet $\mathrm{J}$, et al. Neurotoxic activation of microglia is promoted by a nox1-dependent NADPH oxidase. $\mathrm{J} \mathrm{Neu}$ rosci 28: 12039-12051, 2008.

35. Choi M, Rolle S, Wellner M, Cardoso MC, Scheidereit C, Luft FC, and Kettritz R. Inhibition of NF-kappaB by a TAT-NEMO-binding domain peptide accelerates constitutive apoptosis and abrogates LPS-delayed neutrophil apoptosis. Blood 102: 2259-2267, 2003.

36. Csanyi G, Cifuentes-Pagano E, Ghouleh Al I, Ranayhossaini DJ, Egaña L, Lopes LR, Jackson HM, et al. Nox2 B-loop peptide, Nox2ds, specifically inhibits the NADPH oxidase Nox2. Free Radic Biol Med 51: 1116-1125, 2011.

37. Csanyi G and Pagano PJ. Strategies aimed at Nox4 oxidase inhibition employing peptides from Nox4 B-loop and C-terminus and p22 (phox) N-terminus: an elusive target. Int J Hypertens 2013: 842827, 2013.

38. Cucoranu I, Clempus R, Dikalova A, Phelan PJ, Ariyan S, Dikalov S, and Sorescu D. NAD(P)H oxidase 4 mediates transforming growth factor-beta1-induced differentiation of cardiac fibroblasts into myofibroblasts. Circ Res 97: 900-907, 2005.

39. Dahan I, Molshanski-Mor S, and Pick E. Inhibition of NADPH oxidase activation by peptides mapping within the dehydrogenase region of Nox2-A "peptide walking" study. J Leukoc Biol 91: 501-515, 2012.

40. Dahan I and Pick E. Strategies for identifying synthetic peptides to act as inhibitors of NADPH oxidases, or "all that you did and did not want to know about Nox inhibitory peptides". Cell Mol Life Sci 69: 2283-2305, 2012.

41. Dang PM-C, Stensballe A, Boussetta T, Raad H, Dewas C, Kroviarski Y, Hayem G, et al. A specific p47phox -serine phosphorylated by convergent MAPKs mediates neutrophil NADPH oxidase priming at inflammatory sites. J Clin Invest 116: 2033-2043, 2006.

42. Diatchuk V, Lotan O, Koshkin V, Wikstroem P, and Pick E. Inhibition of NADPH oxidase activation by 4-(2aminoethyl)-benzenesulfonyl fluoride and related compounds. J Biol Chem 272: 13292-13301, 1997.

43. Diaz BA, Shani G, Pass I, Anderson D, Quintavalle M, and Courtneidge SA. Tks5-dependent, nox-mediated generation of reactive oxygen species is necessary for invadopodia formation. Sci Signal 2: ra53, 2008.

44. Ding Y, Chen Z-J, Liu S, Che D, Vetter M, and Chang CH. Inhibition of Nox-4 activity by plumbagin, a plant- 
derived bioactive naphthoquinone. J Pharm Pharmacol 57: 111-116, 2005.

45. Donko A, Ruisanchez E, Orient A, Enyedi B, Kapui R, Péterfi Z, De Deken X, et al. Urothelial cells produce hydrogen peroxide through the activation of Duox1. Free Radic Biol Med 49: 2040-2048, 2010.

46. Dourron HM, Jacobson GM, Park JL, Liu J, Reddy DJ, Scheel ML, and Pagano PJ. Perivascular gene transfer of NADPH oxidase inhibitor suppresses angioplasty-induced neointimal proliferation of rat carotid artery. Am J Physiol Heart Circ Physiol 288: H946-H953, 2005.

47. Drummond GR, Selemidis S, Griendling KK, and Sobey CG. Combating oxidative stress in vascular disease: NADPH oxidases as therapeutic targets. Nat Rev Drug Discov 10: 453-471, 2011.

48. Edmondson DE, Mattevi A, Binda C, Li M, and Hubálek F. Structure and mechanism of monoamine oxidase. Curr Med Chem 11: 1983-1993, 2004.

49. El-Benna J, Dang PM-C, and Périanin A. Peptide-based inhibitors of the phagocyte NADPH oxidase. Biochem Pharmacol 80: 778-785, 2010.

50. Fleming I, Michaelis UR, Bredenkötter D, Fisslthaler B, Dehghani F, Brandes RP, and Busse R. Endotheliumderived hyperpolarizing factor synthase (Cytochrome P450 $2 \mathrm{C} 9$ ) is a functionally significant source of reactive oxygen species in coronary arteries. Circ Res 88: 44-51, 2001.

51. Frantz S, Brandes RP, Hu K, Rammelt K, Wolf J, Scheuermann H, Ertl G, et al. Left ventricular remodeling after myocardial infarction in mice with targeted deletion of the NADPH oxidase subunit gp91PHOX. Basic Res Cardiol 101: 127-132, 2005.

52. Freyhaus ten H, Huntgeburth M, Wingler K, Schnitker J, Bäumer AT, Vantler M, Bekhite MM, et al. Novel Nox inhibitor VAS2870 attenuates PDGF-dependent smooth muscle cell chemotaxis, but not proliferation. Cardiovasc Res 71: 331-341, 2006.

53. Gaggini F, Laleu B, Orchard M, Fioraso-Cartier L, Cagnon L, Houngninou-Molango S, Gradia A, et al. Design, synthesis and biological activity of original pyrazolopyrido-diazepine, -pyrazine and -oxazine dione derivatives as novel dual Nox4/Nox1 inhibitors. Bioorg Med Chem 19: 6989-6999, 2011.

54. Garrido-Urbani S, Jemelin S, Deffert C, Carnesecchi S, Basset O, Szyndralewiez C, Heitz F, et al. Targeting vascular NADPH oxidase 1 blocks tumor angiogenesis through a PPAR $\alpha$ mediated mechanism. PLoS One 6: e14665, 2011.

55. Gatto GJ, Ao Z, Kearse MG, Zhou M, Morales CR, Daniels E, Bradley BT, et al. NADPH oxidase-dependent and -independent mechanisms of reported inhibitors of reactive oxygen generation. J Enzyme Inhib Med Chem 28: 95-104, 2013.

56. Gavazzi G, Bánfi B, Deffert C, Fiette L, Schappi M, Herrmann F, and Krause K-H. Decreased blood pressure in NOX1-deficient mice. FEBS Lett 580: 497-504, 2006.

57. Gianni D, Diaz B, Taulet N, Fowler B, Courtneidge SA, and Bokoch GM. Novel p47(phox)-related organizers regulate localized NADPH oxidase 1 (Nox1) activity. Sci Signal 2: ra54, 2009.

58. Gianni D, Taulet N, Zhang H, DerMardirossian C, Kister J, Martinez L, Roush WR, et al. A novel and specific NADPH oxidase-1 (Nox1) small-molecule inhibitor blocks the formation of functional invadopodia in human colon cancer cells. ACS Chem Biol 5: 981-993, 2010.
59. Girouard H, Park L, Anrather J, Zhou P, and Iadecola C. Angiotensin II attenuates endothelium-dependent responses in the cerebral microcirculation through nox-2-derived radicals. Arterioscler Thromb Vasc Biol 26: 826-832, 2006.

60. Goettsch C, Babelova A, Trummer O, Erben RG, Rauner $\mathrm{M}$, Rammelt S, Weissmann N, et al. NADPH oxidase 4 limits bone mass by promoting osteoclastogenesis. J Clin Invest 123: 4731, 2013.

61. Gorin Y, Block K, Hernandez J, Bhandari B, Wagner B, Barnes JL, and Abboud HE. Nox4 NAD(P)H oxidase mediates hypertrophy and fibronectin expression in the diabetic kidney. J Biol Chem 280: 39616-39626, 2005.

62. Goyal P, Weissmann N, Rose F, Grimminger F, Schäfers HJ, Seeger W, and Hänze J. Identification of novel Nox4 splice variants with impact on ROS levels in A549 cells. Biochem Biophys Res Commun 329: 32-39, 2005.

63. Grasberger $\mathrm{H}$ and Refetoff S. Identification of the maturation factor for dual oxidase. Evolution of an eukaryotic operon equivalent. J Biol Chem 281: 18269-18272, 2006.

64. Gray SP, Di Marco E, Okabe J, Szyndralewiez C, Heitz F, Montezano AC, de Haan JB, et al. NADPH oxidase 1 plays a key role in diabetes mellitus-accelerated atherosclerosis. Circulation 127: 1888-1902, 2013.

65. Green DE, Murphy TC, Kang B-Y, Kleinhenz JM, Szyndralewiez C, Page P, Sutliff RL, et al. The Nox4 inhibitor GKT137831 attenuates hypoxia-induced pulmonary vascular cell proliferation. Am J Respir Cell Mol Biol 47: 718-726, 2012.

66. Griendling KK and FitzGerald GA. Oxidative stress and cardiovascular injury: part II: animal and human studies. Circulation 108: 2034-2040, 2003.

67. Hecker L, Cheng J, and Thannickal VJ. Targeting NOX enzymes in pulmonary fibrosis. Cell Mol Life Sci 69: 2365-2371, 2012.

68. Hecker L, Vittal R, Jones T, Jagirdar R, Luckhardt TR, Horowitz JC, Pennathur S, et al. NADPH oxidase-4 mediates myofibroblast activation and fibrogenic responses to lung injury. Nat Med 15: 1077-1081, 2009.

69. Heim KE, Tagliaferro AR, and Bobilya DJ. Flavonoid antioxidants: chemistry, metabolism and structure-activity relationships. J Nutr Biochem 13: 572-584, 2002.

70. Heumüller S, Wind S, Barbosa-Sicard E, Schmidt HHHW, Busse R, Schröder K, and Brandes RP. Apocynin is not an inhibitor of vascular NADPH oxidases but an antioxidant. Hypertension 51: 211-217, 2008.

71. Hilenski LL, Clempus RE, Quinn MT, Lambeth JD, and Griendling KK. Distinct subcellular localizations of Nox 1 and Nox4 in vascular smooth muscle cells. Arterioscler Thromb Vasc Biol 24: 677-683, 2004.

72. Hoste C, Dumont JE, Miot F, and De Deken X. The type of DUOX-dependent ROS production is dictated by defined sequences in DUOXA. Exp Cell Res 318: 2353-2364, 2012.

73. Ibi M, Matsuno K, Shiba D, Katsuyama M, Iwata K, Kakehi T, Nakagawa T, et al. Reactive oxygen species derived from NOX1/NADPH oxidase enhance inflammatory pain. J Neurosci 28: 9486-9494, 2008.

74. Jacobson GM, Dourron HM, Liu J, Carretero OA, Reddy DJ, Andrzejewski T, and Pagano PJ. Novel NAD $(\mathrm{P}) \mathrm{H}$ oxidase inhibitor suppresses angioplasty-induced superoxide and neointimal hyperplasia of rat carotid artery. Circ Res 92: 637-643, 2003.

75. Janiszewski M, Lopes LR, Carmo AO, Pedro MA, Brandes RP, Santos CXC, and Laurindo FRM. Regulation of $\mathrm{NAD}(\mathrm{P}) \mathrm{H}$ oxidase by associated protein disulfide 
isomerase in vascular smooth muscle cells. $J$ Biol Chem 280: 40813-40819, 2005.

76. Jaquet V, Marcoux J, Forest E, Leidal KG, McCormick S, Westermaier Y, Perozzo R, et al. NADPH oxidase (NOX) isoforms are inhibited by celastrol with a dual mode of action. Br J Pharmacol 164(2b): 507-520, 2011.

77. Jaquet V, Scapozza L, Clark RA, Krause K-H, and Lambeth JD. Small-molecule NOX inhibitors: ROSgenerating NADPH oxidases as therapeutic targets. Antioxid Redox Signal 11: 2535-2552, 2009.

78. Jha JC, Gray SP, Barit D, Okabe J, El-Osta A, Namikoshi $\mathrm{T}$, Thallas-Bonke $\mathrm{V}$, et al. Genetic targeting or pharmacologic inhibition of NADPH oxidase Nox4 provides renoprotection in long-term diabetic nephropathy. J Am Soc Nephrol 2014 [Epub ahead of print]; DOI: 10.1681/ ASN.2013070810

79. Jiang JX, Chen X, Serizawa N, Szyndralewiez C, Page P, Schröder K, Brandes RP, et al. Liver fibrosis and hepatocyte apoptosis are attenuated by GKT137831, a novel NOX4/NOX1 inhibitor in vivo. Free Radic Biol Med 53: 289-296, 2012.

80. Johnson KR, Marden CC, Ward-Bailey P, Gagnon LH, Bronson RT, and Donahue LR. Congenital hypothyroidism, dwarfism, and hearing impairment caused by a missense mutation in the mouse dual oxidase 2 gene, Duox 2 . Mol Endocrinol 21: 1593-1602, 2007.

81. Judkins CP, Diep H, Broughton BRS, Mast AE, Hooker EU, Miller AA, Selemidis S, et al. Direct evidence of a role for Nox2 in superoxide production, reduced nitric oxide bioavailability, and early atherosclerotic plaque formation in ApoE-/-mice. Am J Physiol Heart Circ Physiol 298: H24-H32, 2010.

82. Kallenborn-Gerhardt W, Schröder K, Del Turco D, Lu R, Kynast K, Kosowski J, Niederberger E, et al. NADPH oxidase-4 maintains neuropathic pain after peripheral nerve injury. J Neurosci 32: 10136-10145, 2012.

83. Kao Y-Y, Gianni D, Bohl B, Taylor RM, and Bokoch GM. Identification of a conserved Rac-binding site on NADPH oxidases supports a direct GTPase regulatory mechanism. J Biol Chem 283: 12736-12746, 2008.

84. Kazama K, Anrather J, Zhou P, Girouard H, Frys K, Milner TA, and Iadecola C. Angiotensin II impairs neurovascular coupling in neocortex through NADPH oxidase-derived radicals. Circ Res 95: 1019-1026, 2004.

85. Kennedy JA, Beck-Oldach K, McFadden-Lewis K, Murphy GA, Wong YW, Zhang Y, and Horowitz JD. Effect of the anti-anginal agent, perhexiline, on neutrophil, valvular and vascular superoxide formation. Eur J Pharmacol 531: 13-19, 2006.

86. Kennedy JA, Unger SA, and Horowitz JD. Inhibition of carnitine palmitoyltransferase-1 in rat heart and liver by perhexiline and amiodarone. Biochem Pharmacol 52: 273-280, 1996.

87. Kiss PJ, Knisz J, Zhang Y, Baltrusaitis J, Sigmund CD, Thalmann R, Smith RJH, et al. Inactivation of NADPH oxidase organizer 1 results in severe imbalance. Curr Biol 16: 208-213, 2006.

88. Kleinschnitz $\mathrm{C}$, Grund $\mathrm{H}$, Wingler $\mathrm{K}$, Armitage ME, Jones E, Mittal M, Barit D, et al. Post-stroke inhibition of induced NADPH oxidase type 4 prevents oxidative stress and neurodegeneration. PLoS Biol 8: e1000479, 2010.

89. Kofler PA, Pircher H, Grafenstein von S, Diener T, Höll M, Liedl KR, Siems K, et al. Characterisation of Nox4 inhibitors from edible plants. Planta Med 79: 244-252, 2013.

90. Koizumi H, Fujisawa H, Suehiro E, Shirao S, and Suzuki $M$. Neuroprotective effects of ebselen following forebrain ischemia: involvement of glutamate and nitric oxide. Neurol Med Chir (Tokyo) 51: 337-343, 2011.

91. Kuroda J, Ago T, Matsushima S, Zhai P, Schneider MD, and Sadoshima J. NADPH oxidase 4 (Nox4) is a major source of oxidative stress in the failing heart. Proc Natl Acad Sci U S A 107: 15565-15570, 2010.

92. Laleu B, Gaggini F, Orchard M, Fioraso-Cartier L, Cagnon L, Houngninou-Molango S, Gradia A, et al. First in class, potent, and orally bioavailable NADPH oxidase isoform 4 (Nox4) inhibitors for the treatment of idiopathic pulmonary fibrosis. J Med Chem 53: 7715-7730, 2010.

93. Lassègue B, San Martin A, and Griendling KK. Biochemistry, physiology, and pathophysiology of NADPH oxidases in the cardiovascular system. Circ Res 110: 1364-1390, 2012.

94. Leavy O. Therapeutic antibodies: past, present and future. Nat Rev Immunol 10: 297, 2010.

95. Lee MY, San Martin A, Mehta PK, Dikalova AE, Garrido AM, Datla SR, Lyons E, et al. Mechanisms of vascular smooth muscle NADPH oxidase 1 (Nox1) contribution to injury-induced neointimal formation. Arterioscler Thromb Vasc Biol 29: 480-487, 2009.

96. Li Y, Xu S, Mihaylova MM, Zheng B, Hou X, Jiang B, Park O, et al. AMPK phosphorylates and inhibits SREBP activity to attenuate hepatic steatosis and atherosclerosis in diet-induced insulin-resistant mice. Cell Metab 13: 376-388, 2011.

97. Lipinski CA, Lombardo F, Dominy BW, and Feeney PJ. Experimental and computational approaches to estimate solubility and permeability in drug discovery and development settings. Adv Drug Deliv Rev 46: 3-26, 2001.

98. Liu J, Ormsby A, Oja-Tebbe N, and Pagano PJ. Gene transfer of $\mathrm{NAD}(\mathrm{P}) \mathrm{H}$ oxidase inhibitor to the vascular adventitia attenuates medial smooth muscle hypertrophy. Circ Res 95: 587-594, 2004.

99. Liu J, Yang F, Yang X-P, Jankowski M, and Pagano PJ. $\mathrm{NAD}(\mathrm{P}) \mathrm{H}$ oxidase mediates angiotensin II-induced vascular macrophage infiltration and medial hypertrophy. Arterioscler Thromb Vasc Biol 23: 776-782, 2003.

100. Löhneysen von K, Noack D, Hayes P, Friedman JS, and Knaus UG. Constitutive NADPH oxidase 4 activity resides in the composition of the B-loop and the penultimate C terminus. J Biol Chem 287: 8737-8745, 2012.

101. Looi YH, Grieve DJ, Siva A, Walker SJ, Anilkumar N, Cave AC, Marber M, et al. Involvement of Nox2 NADPH oxidase in adverse cardiac remodeling after myocardial infarction. Hypertension 51: 319-325, 2008.

102. Lyle AN, Deshpande NN, Taniyama Y, Seidel-Rogol B, Pounkova L, Du P, Papaharalambus C, et al. Poldip2, a novel regulator of Nox4 and cytoskeletal integrity in vascular smooth muscle cells. Circ Res 105: 249-259, 2009.

103. Matsuno K, Yamada H, Iwata K, Jin D, Katsuyama M, Matsuki M, Takai S, et al. Nox1 is involved in angiotensin II-mediated hypertension: a study in Nox1-deficient mice. Circulation 112: 2677-2685, 2005.

104. McNally JS, Davis ME, Giddens DP, Saha A, Hwang J, Dikalov S, Jo H, et al. Role of xanthine oxidoreductase and $\mathrm{NAD}(\mathrm{P}) \mathrm{H}$ oxidase in endothelial superoxide production in 
response to oscillatory shear stress. Am J Physiol Heart Circ Physiol 285: H2290-H2297, 2003.

105. Meitzler JL, Hinde S, Bánfi B, Nauseef WM, and Ortiz de Montellano PR. Conserved cysteine residues provide a protein-protein interaction surface in dual oxidase (DUOX) proteins. J Biol Chem 288: 7147-7157, 2013.

106. Meitzler JL and Ortiz de Montellano PR. Caenorhabditis elegans and human dual oxidase 1 (DUOX1) "peroxidase" domains: insights into heme binding and catalytic activity. J Biol Chem 284: 18634-18643, 2009.

107. Meitzler JL and Ortiz de Montellano PR. Structural stability and heme binding potential of the truncated human dual oxidase 2 (DUOX2) peroxidase domain. Arch Biochem Biophys 512: 197-203, 2011.

108. Miller ER, Pastor-Barriuso R, Dalal D, Riemersma RA, Appel LJ, and Guallar E. Meta-analysis: high-dosage vitamin E supplementation may increase all-cause mortality. Ann Intern Med 142: 37-46, 2005.

109. Minnerup J, Sutherland BA, Buchan AM, and Kleinschnitz C. Neuroprotection for stroke: current status and future perspectives. Int J Mol Sci 13: 11753-11772, 2012.

110. Moeller A, Ask K, Warburton D, Gauldie J, and Kolb M. The bleomycin animal model: a useful tool to investigate treatment options for idiopathic pulmonary fibrosis? Int $J$ Biochem Cell Biol 40: 362-382, 2008.

111. Montezano AC, Burger D, Paravicini TM, Chignalia AZ, Yusuf $\mathrm{H}$, Almasri M, He Y, et al. Nicotinamide adenine dinucleotide phosphate reduced oxidase 5 (Nox5) regulation by angiotensin II and endothelin-1 is mediated via calcium/calmodulin-dependent, rac-1-independent pathways in human endothelial cells. Circ Res 106: 1363-1373, 2010.

112. Morand S, Ueyama T, Tsujibe S, Saito N, Korzeniowska A, and Leto TL. Duox maturation factors form cell surface complexes with Duox affecting the specificity of reactive oxygen species generation. FASEB J 23: 1205-1218, 2009.

113. Moreno JC, Bikker H, Kempers MJE, van Trotsenburg ASP, Baas F, de Vijlder JJM, Vulsma T, et al. Inactivating mutations in the gene for thyroid oxidase 2 (THOX2) and congenital hypothyroidism. N Engl J Med 347: 95-102, 2002.

114. Mukherjea D, Jajoo S, Kaur T, Sheehan KE, Ramkumar $\mathrm{V}$, and Rybak LP. Transtympanic administration of short interfering (si)RNA for the NOX3 isoform of NADPH oxidase protects against cisplatin-induced hearing loss in the rat. Antioxid Redox Signal 13: 589-598, 2010.

115. Mukherjea D, Whitworth CA, Nandish S, Dunaway GA, Rybak LP, and Ramkumar V. Expression of the kidney injury molecule 1 in the rat cochlea and induction by cisplatin. Neuroscience 139: 733-740, 2006.

116. Müller A, Cadenas E, Graf P, and Sies H. A novel biologically active seleno-organic compound-I. Glutathione peroxidase-like activity in vitro and antioxidant capacity of PZ 51 (Ebselen). Biochem Pharmacol 33: 3235-3239, 1984.

117. Munson JM, Fried L, Rowson SA, Bonner MY, Karumbaiah L, Diaz B, Courtneidge SA, et al. Anti-invasive adjuvant therapy with imipramine blue enhances chemotherapeutic efficacy against glioma. Sci Transl Med 4: 127ra36, 2012.

118. Musset B, Clark RA, DeCoursey TE, Petheo GL, Geiszt M, Chen Y, Cornell JE, et al. NOX5 in human sperma- tozoa: expression, function, and regulation. $J$ Biol Chem 287: 9376-9388, 2012.

119. Nagase M, Oto J, Sugiyama S, Yube K, Takaishi Y, and Sakato N. Apoptosis induction in HL-60 cells and inhibition of topoisomerase II by triterpene celastrol. Biosci Biotechnol Biochem 67: 1883-1887, 2003.

120. Nagel S, Hadley G, Pfleger K, Grond-Ginsbach C, Buchan AM, Wagner S, and Papadakis M. Suppression of the inflammatory response by diphenyleneiodonium after transient focal cerebral ischemia. J Neurochem $123 \mathrm{Suppl}$ 2: 98-107, 2012.

121. Nakano Y, Bánfi B, Jesaitis AJ, Dinauer MC, Allen L-AH, and Nauseef WM. Critical roles for p22phox in the structural maturation and subcellular targeting of Nox3. Biochem J 403: 97-108, 2007.

122. Niethammer P, Grabher C, Look AT, and Mitchison TJ. A tissue-scale gradient of hydrogen peroxide mediates rapid wound detection in zebrafish. Nature 459: 996999, 2009.

123. Obermayer-Pietsch B, Cavalca V, Eligini S, Brambilla M, Caiani A, Tremoli E, and Colli S. Apocynin prevents cyclooxygenase 2 expression in human monocytes through NADPH oxidase and glutathione redox-dependent mechanisms. Free Radic Biol Med 37: 156-165, 2004.

124. O'Donnell BV, Tew DG, Jones OT, and England PJ. Studies on the inhibitory mechanism of iodonium compounds with special reference to neutrophil NADPH oxidase. Biochem J 290 (Pt 1): 41-49, 1993.

125. O'Donnell VB, Smith GC, and Jones OT. Involvement of phenyl radicals in iodonium inhibition of flavoenzymes. Mol Pharmacol 46: 778-785, 1994.

126. Opitz N, Drummond GR, Selemidis S, Meurer S, and Schmidt HHHW. The 'A's and 'O's of NADPH oxidase regulation: a commentary on "Subcellular localization and function of alternatively spliced Noxo1 isoforms". Free Radic Biol Med 42: 175-179, 2007.

127. Padhye S, Dandawate P, Yusufi M, Ahmad A, and Sarkar FH. Perspectives on medicinal properties of plumbagin and its analogs. Med Res Rev 32: 1131-1158, 2012.

128. Paffenholz R, Bergstrom RA, Pasutto F, Wabnitz P, Munroe RJ, Jagla W, Heinzmann U, et al. Vestibular defects in head-tilt mice result from mutations in Nox3, encoding an NADPH oxidase. Genes Dev 18: 486-491, 2004.

129. Paik Y-H, Iwaisako K, Seki E, Inokuchi S, Schnabl B, Osterreicher $\mathrm{CH}$, Kisseleva $\mathrm{T}$, et al. The nicotinamide adenine dinucleotide phosphate oxidase (NOX) homologues NOX1 and NOX2/gp91(phox) mediate hepatic fibrosis in mice. Hepatology 53: 1730-1741, 2011.

130. Park HS, Jung HY, Park EY, Kim J, Lee WJ, and Bae YS. Cutting edge: direct interaction of TLR4 with $\mathrm{NAD}(\mathrm{P}) \mathrm{H}$ oxidase 4 isozyme is essential for lipopolysaccharideinduced production of reactive oxygen species and activation of NF-kappa B. J Immunol 173: 3589-3593, 2004.

131. Park L, Anrather J, Girouard H, Zhou P, and Iadecola C. Nox2-derived reactive oxygen species mediate neurovascular dysregulation in the aging mouse brain. J Cereb Blood Flow Metab 27: 1908-1918, 2007.

132. Park L, Anrather J, Zhou P, Frys K, Pitstick R, Younkin S, Carlson GA, et al. NADPH-oxidase-derived reactive oxygen species mediate the cerebrovascular dysfunction induced by the amyloid beta peptide. J Neurosci 25: 17691777, 2005. 
133. Park L, Zhou P, Pitstick R, Capone C, Anrather J, Weissmann N, Younkin L, et al. Nox2-derived radicals contribute to neurovascular and behavioral dysfunction in mice overexpressing the amyloid precursor protein. Proc Natl Acad Sci U S A 105: 1347-1352, 2008.

134. Perry BN, Govindarajan B, Bhandarkar SS, Knaus UG, Valo M, Sturk C, Carrillo CO, et al. Pharmacologic blockade of angiopoietin-2 is efficacious against model hemangiomas in mice. J Invest Dermatol 126: 2316-2322, 2006.

135. Petry A, Djordjevic T, Weitnauer M, Kietzmann T, Hess $\mathrm{J}$, and Görlach A. NOX2 and NOX4 mediate proliferative response in endothelial cells. Antioxid Redox Signal 8: 1473-1484, 2006.

136. Pietta P-G. Flavonoids as antioxidants. J Nat Prod 63: 1035-1042, 2000.

137. Pollock JD, Williams DA, Gifford MA, Li LL, Du X, Fisherman J, Orkin SH, et al. Mouse model of X-linked chronic granulomatous disease, an inherited defect in phagocyte superoxide production. Nat Genet 9: 202-209, 1995.

138. Qin F, Siwik DA, Luptak I, Hou X, Wang L, Higuchi A, Weisbrod RM, et al. The polyphenols resveratrol and S17834 prevent the structural and functional sequelae of diet-induced metabolic heart disease in mice. Circulation 125: 1757-1764, S1-S6, 2012.

139. Radermacher KA, Wingler K, Kleikers P, Altenhöfer S, Jr., Hermans J, Kleinschnitz C, and Schmidt HHW The 1027th target candidate in stroke: will NADPH oxidase hold up? Exp Transl Stroke Med 4: 11, 2012.

140. Radermacher KA, Wingler K, Langhauser F, Altenhöfer S, Kleikers P, Hermans JJR, Hrabě de Angelis M, et al. Neuroprotection after stroke by targeting NOX4 as a source of oxidative stress. Antioxid Redox Signal 18: 1418-1427, 2013.

141. Rajasekaran NS, Connell P, Christians ES, Yan L-J, Taylor RP, Orosz A, Zhang XQ, et al. Human alpha Bcrystallin mutation causes oxido-reductive stress and protein aggregation cardiomyopathy in mice. Cell 130: 427-439, 2007.

142. Rammelt S and Pawliczak R. Apocynin: molecular aptitudes. Mediat Inflamm 2008: 106507, 2008.

143. Ranayhossaini DJ, Rodriguez AI, Sahoo S, Chen BB, Mallampalli RK, Kelley EE, Csanyi G, et al. Selective recapitulation of conserved and non-conserved regions of putative NOXA1 activation domain confers isoformspecific inhibition of Nox1 oxidase, attenuation of endothelial cell Nox and migration. J Biol Chem 2013.

144. Raz L, Zhang Q-G, Zhou C-F, Han D, Gulati P, Yang L-C, Yang F, et al. Role of Rac1 GTPase in NADPH oxidase activation and cognitive impairment following cerebral ischemia in the rat. PLoS One 5: e12606, 2010.

145. Rey FE, Cifuentes ME, Kiarash A, Quinn MT, and Pagano PJ. Novel competitive inhibitor of NAD(P)H oxidase assembly attenuates vascular $\mathrm{O}(2)(-)$ and systolic blood pressure in mice. Circ Res 89: 408-414, 2001.

146. Rigutto S, Hoste C, Grasberger H, Milenkovic M, Communi D, Dumont JE, Corvilain B, et al. Activation of dual oxidases Duox1 and Duox2: differential regulation mediated by camp-dependent protein kinase and protein kinase C-dependent phosphorylation. J Biol Chem 284: 6725-6734, 2009.

147. Robak J and Gryglewski RJ. Flavonoids are scavengers of superoxide anions. Biochem Pharmacol 37: 837-841, 1988.
148. Salminen A, Lehtonen M, Paimela T, and Kaarniranta K. Celastrol: molecular targets of thunder god vine. Biochem Biophys Res Commun 394: 439-442, 2010.

149. Sareila O, Kelkka T, Pizzolla A, Hultqvist M, and Holmdahl R. NOX2 complex-derived ROS as immune regulators. Antioxid Redox Signal 15: 2197-2208, 2011.

150. Schildknecht S, Weber A, Gerding HR, Pape R, Robotta M, Drescher M, Marquardt A, et al. The NOX1/4 inhibitor GKT136901 as selective and direct scavenger of peroxynitrite. Curr Med Chem 21: 365-76, 2013.

151. Schlüter T, Steinbach AC, Steffen A, Rettig R, and Grisk O. Apocynin-induced vasodilation involves Rho kinase inhibition but not NADPH oxidase inhibition. Cardiovasc Res 80: 271-279, 2008.

152. Schröder K, Zhang M, Benkhoff S, Mieth A, Pliquett R, Kosowski J, Kruse C, et al. Nox4 is a protective reactive oxygen species generating vascular NADPH oxidase. Circ Res 110: 1217-1225, 2012.

153. Scotton CJ and Chambers RC. Bleomycin revisited: towards a more representative model of IPF? Am J Physiol Lung Cell Mol Physiol 299: L439-L441, 2010.

154. Sedeek M, Callera G, Montezano A, Gutsol A, Heitz F, Szyndralewiez C, Page P, et al. Critical role of Nox4based NADPH oxidase in glucose-induced oxidative stress in the kidney: implications in type 2 diabetic nephropathy. Am J Physiol Renal Physiol 299: F1348F1358, 2010.

155. Sedeek M, Gutsol A, Montezano AC, Burger D, Nguyen Dinh Cat A, Kennedy CRJ, Burns KD, et al. Renoprotective effects of a novel Nox1/4 inhibitor in a mouse model of Type 2 diabetes. Clin Sci 124: 191-202, 2013.

156. Sedeek M, Montezano AC, Hebert RL, Gray SP, Di Marco E, Jha JC, Cooper ME, et al. Oxidative stress, Nox isoforms and complications of diabetes-potential targets for novel therapies. J Cardiovasc Transl Res 5: 509-518, 2012.

157. Selemidis S, Sobey CG, Wingler K, Schmidt HHHW, and Drummond GR. NADPH oxidases in the vasculature: molecular features, roles in disease and pharmacological inhibition. Pharmacol Ther 120: 254-291, 2008.

158. Sellers KW, Sun C, Diez-Freire C, Waki H, Morisseau C, Falck JR, Hammock BD, et al. Novel mechanism of brain soluble epoxide hydrolase-mediated blood pressure regulation in the spontaneously hypertensive rat. FASEB $J 19$ : 626-628, 2005.

159. Serrander L, Jaquet V, Bedard K, Plastre O, Hartley O, Arnaudeau S, Demaurex N, et al. NOX5 is expressed at the plasma membrane and generates superoxide in response to protein kinase C activation. Biochimie 89: 1159-1167, 2007.

160. Sheehan AL, Carrell S, Johnson B, Stanic B, Bánfi B, and Miller FJ. Role for Nox1 NADPH oxidase in atherosclerosis. Atherosclerosis 216: 321-326, 2011.

161. Shin YS, Song SJ, Kang SU, Hwang HS, Choi JW, Lee $\mathrm{BH}$, Jung Y-S, et al. A novel synthetic compound, 3amino-3-(4-fluoro-phenyl)-1H-quinoline-2,4-dione, inhibits cisplatin-induced hearing loss by the suppression of reactive oxygen species: in vitro and in vivo study. $\mathrm{Neu}$ roscience 232C: 1-12, 2012.

162. Shionogi and Co., Ltd. 2006. US 2006/0089362 Patent Office.

163. Skulachev VP. Role of uncoupled and non-coupled oxidations in maintenance of safely low levels of oxygen and 
its one-electron reductants. $Q$ Rev Biophys 29: 169-202, 1996.

164. Smith SME, Min J, Ganesh T, Diebold B, Kawahara T, Zhu Y, McCoy J, et al. Ebselen and congeners inhibit NADPH oxidase 2-dependent superoxide generation by interrupting the binding of regulatory subunits. Chem Biol 19: 752-763, 2012.

165. Stielow C, Catar RA, Muller G, Wingler K, Scheurer P, Schmidt HHHW, and Morawietz H. Novel Nox inhibitor of oxLDL-induced reactive oxygen species formation in human endothelial cells. Biochem Biophys Res Commun 344: 200-205, 2006.

166. Stolk J, Hiltermann TJ, Dijkman JH, and Verhoeven AJ. Characteristics of the inhibition of NADPH oxidase activation in neutrophils by apocynin, a methoxysubstituted catechol. Am J Respir Cell Mol Biol 11: 95-102, 1994.

167. Sun Q-A, Hess DT, Wang B, Miyagi M, and Stamler JS. Off-target thiol alkylation by the NADPH oxidase inhibitor 3-benzyl-7-(2-benzoxazolyl)thio-1,2,3-triazolo[4,5d]pyrimidine (VAS2870). Free Radic Biol Med 52: $1897-$ 1902, 2012.

168. Suzuki Y, Hattori K, Hamanaka J, Murase T, Egashira Y, Mishiro K, Ishiguro M, et al. Pharmacological inhibition of TLR4-NOX4 signal protects against neuronal death in transient focal ischemia. Sci Rep 2: 896, 2012.

169. Takac I, Schröder K, Zhang L, Lardy B, Anilkumar N, Lambeth JD, Shah AM, et al. The E-loop is involved in hydrogen peroxide formation by the NADPH oxidase Nox4. J Biol Chem 286: 13304-13313, 2011.

170. Tirone F and Cox JA. NADPH oxidase 5 (NOX5) interacts with and is regulated by calmodulin. FEBS Lett 581: 1202-1208, 2007.

171. Ueno N, Takeya R, Miyano K, Kikuchi H, and Sumimoto H. The NADPH oxidase Nox3 constitutively produces superoxide in a p22phox-dependent manner: its regulation by oxidase organizers and activators. J Biol Chem 280: 23328-23339, 2005.

172. Ueyama T, Geiszt M, and Leto TL. Involvement of Rac1 in activation of multicomponent Nox1- and Nox3based NADPH oxidases. Mol Cell Biol 26: 2160-2174, 2006.

173. van der Vliet A. NADPH oxidases in lung biology and pathology: host defense enzymes, and more. Free Radic Biol Med 44: 938-955, 2008.

174. Vásquez-Vivar J, Kalyanaraman B, Martásek P, Hogg N, Masters BS, Karoui H, Tordo P, et al. Superoxide generation by endothelial nitric oxide synthase: the influence of cofactors. Proc Natl Acad Sci U S A 95: 9220-9225, 1998.

175. Vendrov AE, Hakim ZS, Madamanchi NR, Rojas M, Madamanchi C, and Runge MS. Atherosclerosis is attenuated by limiting superoxide generation in both macrophages and vessel wall cells. Arterioscler Thromb Vasc Biol 27: 2714-2721, 2007.

176. Vendrov AE, Madamanchi NR, Niu X-L, Molnar KC, Runge M, Szyndralewiez C, Page P, et al. NADPH oxidases regulate CD44 and hyaluronic acid expression in thrombin-treated vascular smooth muscle cells and in atherosclerosis. J Biol Chem 285: 26545-26557, 2010.

177. Weaver M, Liu J, Pimentel D, Reddy DJ, Harding P, Peterson EL, and Pagano PJ. Adventitial delivery of dominant-negative p67phox attenuates neointimal hyperplasia of the rat carotid artery. Am J Physiol Heart Circ Physiol 290: H1933-H1941, 2006.

178. Weissmann N, Sydykov A, Kalwa H, Storch U, Fuchs B, Mederos Y Schnitzler M, Brandes RP, et al. Activation of TRPC6 channels is essential for lung ischaemiareperfusion induced oedema in mice. Nat Commun 3: 649, 2012.

179. Wilkinson-Berka JL, Deliyanti D, Rana I, Miller AG, Agrotis A, Armani R, Szyndralewiez C, et al. NADPH oxidase, NOX1, mediates vascular injury in ischemic retinopathy. Antioxid Redox Signal 20: 2726-2740, 2014.

180. Williams HC and Griendling KK. NADPH oxidase inhibitors: new antihypertensive agents? J Cardiovasc Pharmacol 50: 9-16, 2007.

181. Wind S, Beuerlein K, Eucker T, Müller H, Scheurer P, Armitage ME, Ho H, et al. Comparative pharmacology of chemically distinct NADPH oxidase inhibitors. $\mathrm{Br} J$ Pharmacol 161: 885-898, 2010.

182. Wingler K, Hermans JJR, Schiffers P, Moens A, Paul M, and Schmidt HHHW. NOX1, 2, 4, 5: counting out oxidative stress. $\mathrm{Br} J$ Pharmacol 164: 866-883, 2011.

183. Xu S, Jiang B, Hou X, Shi C, Bachschmid MM, Zang M, Verbeuren TJ, et al. High-fat diet increases and the polyphenol, S17834, decreases acetylation of the sirtuin1-dependent lysine-382 on p53 and apoptotic signaling in atherosclerotic lesion-prone aortic endothelium of normal mice. J Cardiovasc Pharmacol 58: 263-271, 2011.

184. Yamaguchi T, Sano K, Takakura K, Saito I, Shinohara Y, Asano $\mathrm{T}$, and Yasuhara $\mathrm{H}$. Ebselen in acute ischemic stroke: a placebo-controlled, double-blind clinical trial. Ebselen Study Group. Stroke 29: 12-17, 1998.

185. Yang H, Chen D, Cui QC, Yuan X, and Dou QP. Celastrol, a triterpene extracted from the Chinese "Thunder of God Vine," is a potent proteasome inhibitor and suppresses human prostate cancer growth in nude mice. Cancer Res 66: 4758-4765, 2006.

186. Yogi A, Mercure C, Touyz J, Callera GE, Montezano ACI, Aranha AB, Tostes RC, et al. Renal redox-sensitive signaling, but not blood pressure, is attenuated by Nox 1 knockout in angiotensin II-dependent chronic hypertension. Hypertension 51: 500-506, 2008.

187. Zang M, Xu S, Maitland-Toolan KA, Zuccollo A, Hou X, Jiang B, Wierzbicki M, et al. Polyphenols stimulate AMPactivated protein kinase, lower lipids, and inhibit accelerated atherosclerosis in diabetic LDL receptor-deficient mice. Diabetes 55: 2180-2191, 2006.

188. Zembowicz A, Hatchett RJ, Radziszewski W, and Gryglewski RJ. Inhibition of endothelial nitric oxide synthase by ebselen. Prevention by thiols suggests the inactivation by ebselen of a critical thiol essential for the catalytic activity of nitric oxide synthase. J Pharmacol Exp Ther 267: 1112-1118, 1993.

189. Zhang L, Nguyen MVC, Lardy B, Jesaitis AJ, Grichine A, Rousset F, Talbot M, et al. New insight into the Nox4 subcellular localization in HEK293 cells: first monoclonal antibodies against Nox4. Biochimie 93: 457-468, 2011.

190. Zhang M, Brewer AC, Schröder K, Santos CXC, Grieve DJ, Wang M, Anilkumar N, et al. NADPH oxidase-4 mediates protection against chronic load-induced stress in 
mouse hearts by enhancing angiogenesis. Proc Natl Acad Sci U S A 107: 18121-18126, 2010.

191. Zhang Q-G, Raz L, Wang R, Han D, De Sevilla L, Yang $\mathrm{F}$, Vadlamudi RK, et al. Estrogen attenuates ischemic oxidative damage via an estrogen receptor alpha-mediated inhibition of NADPH oxidase activation. J Neurosci 29: 13823-13836, 2009.

192. Zhang R, Brennan M-L, Shen Z, MacPherson JC, Schmitt D, Molenda CE, and Hazen SL. Myeloperoxidase functions as a major enzymatic catalyst for initiation of lipid peroxidation at sites of inflammation. J Biol Chem 277: 46116-46122, 2002.

193. Zhang X, Min X, Li C, Benjamin IJ, Qian B, Zhang X, Ding $\mathrm{Z}$, et al. Involvement of reductive stress in the cardiomyopathy in transgenic mice with cardiac-specific overexpression of heat shock protein 27. Hypertension 55: 1412-1417, 2010.

194. Zhou M-S, Hernandez Schulman I, Pagano PJ, Jaimes EA, and Raij L. Reduced NAD $(\mathrm{P}) \mathrm{H}$ oxidase in low renin hypertension: link among angiotensin II, atherogenesis, and blood pressure. Hypertension 47: 81-86, 2006.

195. Zhou X, Bohlen HG, Miller SJ, and Unthank JL. $\mathrm{NAD}(\mathrm{P}) \mathrm{H}$ oxidase-derived peroxide mediates elevated basal and impaired flow-induced NO production in SHR mesenteric arteries in vivo. Am J Physiol Heart Circ Physiol 295: H1008-H1016, 2008.

Address correspondence to Dr. Harald H.H.W. Schmidt Department of Pharmacology, Cardiovascular Research Institute Maastricht (CARIM)

Maastricht University

Universiteitssingel 50

Maastricht 6229 ER The Netherlands

E-mail: h.schmidt@maastrichtuniversity.nl

Date of first submission to ARS Central, December 20, 2013; date of acceptance, January 2, 2014.

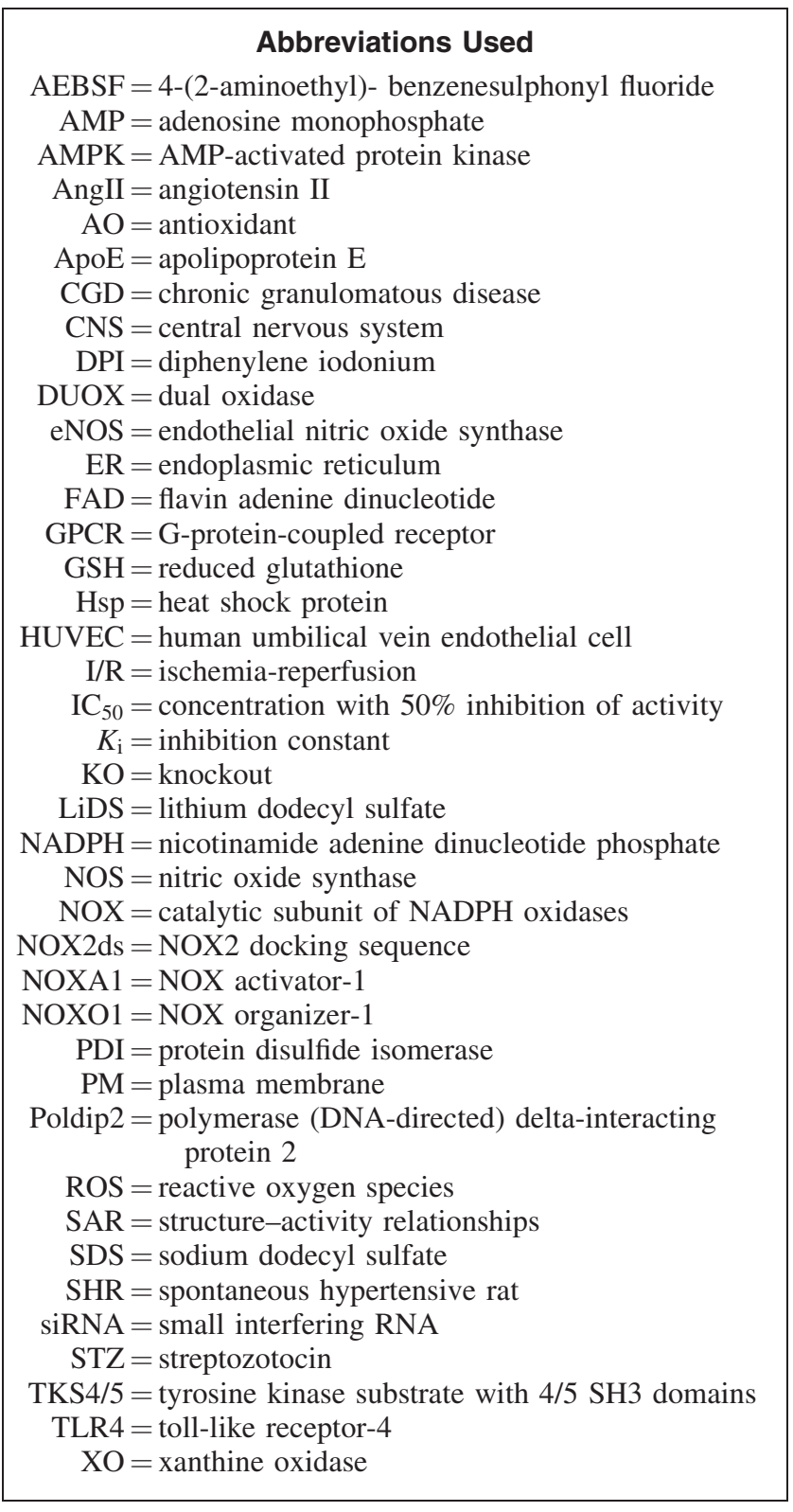

